Published in final edited form as:

Annu Rev Biophys. 2013 ; 42: 217-239. doi:10.1146/annurev-biophys-083012-130404.

\title{
Molecular mechanisms of RNA interference
}

\author{
Ross Wilson ${ }^{2}$ and Jennifer A. Doudna ${ }^{1,2,3,4}$ \\ ${ }^{1}$ Howard Hughes Medical Institute, University of California, Berkeley, CA 94720 \\ 2Department of Molecular and Cell Biology, University of California, Berkeley, CA 94720 \\ ${ }^{3}$ Department of Chemistry, University of California, Berkeley, CA 94720 \\ ${ }^{4}$ Physical Biosciences Division, Lawrence Berkeley National Laboratory, Berkeley, CA 94720
}

\begin{abstract}
Small RNA molecules regulate eukaryotic gene expression during development and in response to stresses including viral infection. Specialized ribonucleases and RNA binding proteins govern the production and action of small regulatory RNAs. After initial processing in the nucleus by Drosha, pre-miRNAs are transported to the cytoplasm, where Dicer cleavage generates mature microRNAs (miRNAs) and short interfering RNAs (siRNAs). These double-stranded products assemble with Argonaute proteins such that one strand is preferentially selected and used to guide sequencespecific silencing of complementary target mRNAs by endonucleolytic cleavage or translational repression. Molecular structures of Dicer and Argonaute proteins, and RNA-bound complexes, have offered exciting insight into the mechanisms operating at the heart of RNA silencing pathways.
\end{abstract}

\section{Keywords}

miRNA; siRNA; RNAi; dsRNA; Dicer; Argonaute

\section{A BIOLOGICAL VIEW OF RNA INTERFERENCE}

\section{- Small regulatory RNAs in cellular function and dysfunction}

The discovery of RNA interference (RNAi) revolutionized our understanding of gene regulation by revealing an array of related pathways in which small 20-30 nucleotide (nt) non-coding RNAs and their associated proteins control the expression of genetic information (7). In processes that are widespread in plants and animals (75), each small RNA associates with an Argonaute family protein to form a sequence-specific gene-silencing ribonucleoprotein (RNP) with specificity conferred by base-pairing between the small (guide) RNA and its target mRNA.

Contact doudna@berkeley.edu. DISCLOSURE STATEMENT

The authors are not aware of any affiliations, memberships, funding, or financial holdings that might be perceived as affecting the objectivity of this review. 
As much as $5 \%$ of the human genome is dedicated to encoding and producing the $>1,000$ miRNAs that regulate at least $30 \%$ of our genes $(23,36)$. RNAi pathways transcend mere expansion of the gene regulation toolkit: they confer a qualitative change in the way cellular networks are managed. This prompts consideration of the fascinating possibility that we owe our sentience to small RNAs, as the number of miRNAs present in a genome appears to correlate with the complexity of the organism (3).

RNAi is charged with controlling vital processes including cell growth, tissue differentiation, heterochromatin formation and cell proliferation. Accordingly, RNAi dysfunction is linked to cardiovascular disease, neurological disorders and many types of cancer (49). Immense effort has been exerted in hopes of developing siRNA-based therapies to combat genetic or viral disease. Although the field shows great promise, challenges with delivery as well as harmful off-target effects have prevented any such drug from reaching the market so far (13). In parallel with this effort, advances in mechanistic understanding of these pathways have been impressive, providing increasing insights into the molecular structure and activities responsible for small RNA-mediated genetic control. Such insights will be essential to future success in harnessing RNAi and related processes for both therapeutics and genome engineering.

This review focuses primarily on structural and mechanistic studies of the human miRNA pathway, with limited discussion of recent progress on the siRNA and piRNA pathways. In many cases, macromolecular structures and interactions that are part of miRNA pathways are analogous to those responsible for siRNA activities. In contrast, the key molecular players involved in the germ line-specific piRNA pathway have remained so mysterious that little biophysical study has been possible until very recently.

\section{- Biogenesis and action of miRNA \& siRNA}

The three pathways of RNAi (miRNA, siRNA, piRNA) share a common mode of action: the minimal effector is an RNP complex comprising an Argonaute family protein bound to a single stranded 20-30 nt RNA that grants specificity via base-pairing interactions with the gene target. In miRNA and siRNA pathways, this is known as the RNA-induced silencing complex (RISC) and drives silencing of a target mRNA via degradation and/or transcriptional repression (Figure 1a). The cellular origins of miRNA and siRNA are somewhat disparate: miRNAs are derived from the genome, whereas siRNAs may be endogenous or arise via viral infection or other exogenous sources (7). Another key difference occurs in the double-stranded RNA (dsRNA) precursors of each: siRNA duplexes feature perfect base pairing while miRNA helices contain mismatches and more extended terminal loops. Despite their differing origins, these processing pathways converge once either type of RNA assembles into the RISC.

Typically, the genesis of a miRNA occurs in the nucleus with a transcript known as a primary miRNA (pri-miRNA); such transcripts are at least 1,000 nt long, containing single or clustered double-stranded hairpins that bear single-stranded $5^{\prime}$ and $3^{\prime}$ overhangs and $\sim 10$ nt distal loops (69). A pri-miRNA is cropped by the microprocessor complex, comprising Drosha, an RNase III family enzyme, and DiGeorge syndrome critical region gene 8 (DGCR8), a protein containing two double-stranded RNA-binding domains (dsRBDs) (40). 
DGCR8 recognizes the pri-miRNA's junction of stem and single-stranded RNA, which likely aids in positioning Drosha for the endonucleolytic cleavage it performs on the stem $\sim 11$ base pairs (bp) from the junction (30). The resulting $\sim 65-70 \mathrm{nt}$ precursor (pre-miRNA) associates with transport facilitators Exportin-5 and RanGTP and is exported to the cytoplasm (50).

In the cytoplasm, the processing pathways converge for endogenous miRNAs and for typically exogenous siRNA. Both types of RNAi precursor are trimmed down to a dsRNA duplex of the appropriate size for loading onto an Argonaute protein; this is typically performed by a Dicer enzyme. Dicers are large endoribonucleases containing a helicase domain and an internally-dimerized pair of RNase III domains, but this composition can vary between organisms (75). Before or after they are excised, introns may serve as viable substrates for microprocessor or Dicer, acting as pri- or pre-miRNAs, respectively (40). In plants, dicing precedes methylation of the $3^{\prime}$-terminal nucleotide's 2 '-hydroxyl by the methyltransferase HEN1 (33). The resulting dsRNA is a duplex of 21-25 nt strands, bearing a $2 \mathrm{nt}$ overhang at each $3^{\prime}$-terminus and a phosphate group at each recessed $5^{\prime}$-terminus (73). With this enzymatic step and the subsequent loading onto Argonaute, Dicer may be aided by a dsRNA-binding protein (dsRBP) such as TAR RNA-binding protein (TRBP). These three proteins (Dicer, Argonaute, and a dsRBP) constitute a minimal RISC-loading complex (RLC), which is responsible for generating diced dsRNA and loading it onto Argonaute (56). Once the dsRNA helix is presented to Argonaute, the $3^{\prime}$-terminus and $5^{\prime}$ phosphate of the guide strand are bound by the protein's PAZ and MID domains, respectively, generating the RISC. RISC loading is coincident with the strand selection step, wherein one strand of the duplex is bound to Argonaute to direct silencing and the other strand is discarded. These strands are known as the guide and passenger strands, respectively, and their selection is a key determinant of the silencing that follows. The transient complex consisting of Argonaute bound to the guide strand and a passenger strand that has yet to be cleaved and/or dissociate is known as the pre-RISC. In the case of the miRNA pathway, the strand from the duplex that is most commonly loaded is known as the miRNA while the opposing strand is termed the miRNA*.

The RISC performs cellular surveillance, binding single-stranded RNA (ssRNA) such as mRNA with complementarity to the Argonaute-bound guide strand. Guide strand nucleotides $2-6$ constitute the seed sequence and initialize binding to the target. This binding need not involve perfect complementarity, and the extent of base pairing influences how the subsequent silencing will transpire. In cases of perfect complementarity, target cleavage can occur if the Argonaute present bears catalytic activity (as is true for just one of the four human Ago proteins, Ago2). The RISC can also induce non-endonucleolytic translational repression before or after initiation; this may be followed by deadenylation and degradation. Additional cellular machinery is responsible for the processes downstream of target binding, and the Ago-binding protein GW182 is a key mediator in recruiting these additional components to the RISC and in localizing silencing activity to cytoplasmic loci known as processing $(\mathrm{P})$ bodies (19). These complicated gene silencing mechanisms were initially unclear and appeared daunting, but a recent surge of information has shed light on major pathways and is reviewed in (21). 


\section{ACTIVITY, STRUCTURE, AND INTERACTIONS OF mIRNA PATHWAY PROTEINS}

- Microprocessor

Before their export to the cytoplasm for further processing and silencing, nuclear primiRNAs must be recognized and cleaved. These respective tasks are carried out by the proteins Drosha and DGCR8 (known as Pasha in invertebrates), which together constitute the microprocessor complex. As with Dicer, Drosha proteins belong to the RNase III family, whose members contain a dimeric active site (55). The minimal endonucleolytic active site is composed of two 100-amino acid (aa) RNase III domains; in bacterial or yeast (Class 1) enzymes, these domains result from homodimerization of two identical protomers. In contrast, the pair of RNase III domains composing the active sites of Drosha (Class 2) and Dicer (Class 3) enzymes are provided as an adjacent pair on the same chain, forming a pseudo-dimer. Regardless of a given protein's class, the most C-terminal RNase III domain is followed by a $\sim 70$-aa dsRBD domain, which confers sequence-nonspecific dsRNA binding. All three classes of RNase III enzyme utilize each catalytic domain to cleave a single strand of the dsRNA substrate, working in unison to produce new dsRNA termini bearing $2 \mathrm{nt} 3^{\prime}$ overhangs and $5^{\prime}$ phosphate groups (55).

In the context of the microprocessor complex, Drosha performs cleavage consistent with its identity as an RNase III enzyme (45). The portion of the protein $\mathrm{N}$-terminal to its paired catalytic domains is typical of a Class 2 RNase III in that it contains a proline-rich region, but the function of this portion remains unknown (Figure 2a). Drosha's C-terminal dsRBD is canonical in its sequence and tertiary structure (59) and is required for pri-miRNA processing in vivo (2) but does not appear to play a substantial role in substrate binding or recognition in vitro (95), tasks instead performed by DGCR8 (30). Accordingly, Drosha cleaves pri-miRNAs indiscriminately in the absence of DGCR8 (26). DGCR8's dsRNA binding is carried out by a pair of dsRBDs in its $\mathrm{C}$-terminal half; its $\mathrm{N}$-terminus contains a structurally-characterized, heme-binding dimerization domain (74) and is otherwise of unknown structure and function, though its tryptophan-rich region has been hypothesized to interact with the proline-rich region of Drosha's N-terminus (Figure 2a) (26).

The structure of the DGCR8 core-The crystal structure of DGCR8's dsRBD pair revealed two domains, each adopting the traditional fold: an $\alpha / \beta$ sandwich with the terminal $a$-helices resting atop a three-stranded $\beta$-sheet (Figure $2 b$ ). These two domains are surrounded by several additional secondary structural elements that contribute to a wellordered quaternary structure (the DGCR8 core), orienting the two dsRBD domains with respect to each other without disrupting either individual structure from the canonical geometry. The DGCR8 domains were crystallized in the absence of RNA, yet concomitant binding studies via eletrophoretic mobility shift assay (EMSA) and fluorescence resonance energy transfer (FRET) revealed that the dsRBD domains interact primarily with dsRNA but not with ssRNA. While the dsRNA affinity is anticipated for a pair of orthodox dsRBDs, the lack of affinity for ssRNA is somewhat surprising since the DGCR8 binding site is a junction between a helical stem and two flanking strands of ssRNA (stem-ssRNA junction) (Figure 1a). This binding site is inferred based on cleavage assays that reveal DGCR8 to be 
the factor responsible for correctly positioning and orienting the microprocessor for Droshacatalyzed cleavage $\sim 11$ bp from the stem-ssRNA junction (30), but it remains unclear which region of DGCR8 or Drosha is responsible for recognition of the flanking ssRNA.

Without detectable affinity for ssRNA, it is unknown how DGCR8 is so reliably positioned at the stem-ssRNA junction instead of binding promiscuously along the pri-miRNA stem. Curiously, the only reported evidence for ssRNA-specific binding by any microprocessor component implicates the serine/arginine rich region of Drosha's N-terminus (96), though this probably explains the microprocessor's preference for a distal $~ 10$-nt loop on the primiRNA substrate rather than addressing DGCR8's positioning at the stem-ssRNA junction.

Higher-order assemblies between the microprocessor and pri-miRNA-Efforts are underway to model the active state of the microprocessor complex interacting with its pri-miRNA substrates. The two dsRBDs of the DGCR8 core offer their RNA-binding surfaces such that they cannot simultaneously bind a pri-miRNA without a major distortion from A-form geometry (Figure 2b); FRET-based evidence for such bending has been reported, but the possibility remains that the DGCR8 core's two domains bind to separate pri-miRNAs (76). Evidence for such multimeric assembly is provided by an electron tomography study of the association between DGCR8 and a pri-miRNA, which revealed a $\sim 370 \mathrm{kDa}$ particle consistent with a single pri-miRNA bound to six DGCR8 protomers or four pri-miRNA:DGCR8 heterodimers, among other configurations (22). Such larger assemblies might be expected since many miRNAs originate from pri-miRNAs clustered on a single transcript.

Recent cellular imaging studies have precisely tracked the nuclear localization of Drosha and DGCR8 over time, revealing that they colocalize simultaneously on unspliced, intronic pri-miRNA and that Drosha tends to dissociate after cleavage while DGCR8 is likely to remain bound to the processed pre-miRNAs before their nuclear export (2). The former finding builds on an earlier report that the microprocessor associates with the spliceosome, providing mounting evidence that cropping takes place before splicing is complete (38).

- Dicer

The Dicer family of class 3 RNase III enzymes is vital in siRNA and miRNA pathways. These proteins generate dsRNAs suitable for loading onto an Argonaute protein, a process in which Dicer may participate as part of the RLC. Dicer's active center is derived from bacterial class 1 RNase III enzymes, which comprise an RNase III domain with a C-terminal dsRBD (75). Bacterial enzymes dimerize to achieve concerted cleavage of both strands of a dsRNA substrate. Class 3 Dicer enzymes accomplish similar dsRNA cleavage using a pseudo-dimer of RNase III domains on a single polypeptide with a single C-terminal dsRBD (55). N-terminal of these paired active sites is a PAZ domain (named for its presence in PIWI, Argonaute, and Zwille proteins), which is responsible for recognizing the dsRNA end characteristic of RNAi intermediates (Figure 3a) (53). The PAZ and RNase III domains act together as a molecular ruler to mete out diced strands of RNA appropriate for a given organism's silencing machinery, as will be discussed in greater depth below. 
A distinguishing characteristic of Dicer is the superfamily 2 helicase domain often found at its N-terminus. This $\geq 600$ aa domain belongs to the eukaryotic RIG-I family of helicases, which is characterized by a bilobal architecture comprising $\mathrm{DExD} / \mathrm{H}$ and Helicase $\mathrm{C}$ regions, the former of which is expected to bind and potentially hydrolyze ATP (98). The function of this helicase domain is still being defined in the case of humans, while for Drosophila's pair of Dicer enzymes the helicase domain can recognize either miRNA or siRNA precursors (vide infra). In some cases Dicer's helicase domain also contains a binding site for a dsRBP such as TRBP in humans.

Dicer's domain structure varies between organisms, yet its principal dicing function is preserved. Giardia intestinalis Dicer lacks a helicase domain (54), while the budding yeast equivalent is further pared down, lacking a PAZ domain and bearing a since RNase III domain (90). These helicase-lacking enzymes may have lost dsRBP binding capability as well, considering the aforementioned interface. In a case of specialization, Drosophila employs a pair of Dicer enzymes and corresponding dsRBPs to create parallel processing pathways for siRNAs and miRNAs (9). Plants such as Arabidopsis take such specialization further with four Dicer-like proteins (DCL1-4): DCL1 for generation of $21 \mathrm{nt}$ miRNAs and DCL2-4 for processing of siRNAs of 22, 24, or $21 \mathrm{nt}$, respectively (68).

Dicing activity-Dicer's principal function is to recognize dsRNA precursors from the RNAi pathway and sever both strands to generate dsRNAs of a specific length, typically 21$25 \mathrm{nt}$ (4). Recognition and cleavage of a generic segment of dsRNA helix can be expected of any enzyme system bearing a pair of RNase III domains. These dimerized domains bear a flat, positively-charged surface that can accommodate a long RNA helix in addition to two active sites that each bear four acidic residues that coordinate two $\mathrm{Mg}^{2+}$ ions used in phosphodiester hydrolysis of each RNA strand (Figure $3 b)(25,79)$. The dsRNA terminus characteristic of RNAi pathway precursors (a 2-nt overhang on the 3 '-terminus and a phosphate-bearing $5^{\prime}$-terminus) can be recognized by the Dicer's PAZ domain, as was revealed by a crystal structure of human Argonaute's similar PAZ domain bound to one such RNA terminus (vide infra) (53).

The RNA-measuring component of Dicer's function was revealed upon structure determination of the Giardia version of the protein, wherein the PAZ domain is located $65 \AA$ from the catalytic center (Figure $3 b$ ) (54). This distance corresponds to the length spanned by $\sim 25$ bp of dsRNA, which is consistent with the 25-27 nt products generated by Giardia Dicer. The distance between the end-binding PAZ domain and the RNase III cleavage sites is determined by structural orientation of the domains; these domains likely undergo rearrangement in other Dicer incarnations to produce the observed products of differing lengths. Giardia Dicer lacks the typical N-terminal helicase and C-terminal dsRBD domains, suggesting that these elements fulfill roles supplementary to dicing (54). This is consistent with the observation that a truncated form of human Dicer lacking helicase and dsRBD domains retained dicing activity (51). More recent studies show that the dsRBD can rescue activity in a form of human Dicer lacking its PAZ domain, though the resulting products vary in length as might be expected (52). 
Also lacking a helicase domain is Dicer of the budding yeast Kluyveromyces polysporus, Dcr1, which represents an extremely pared down version of the enzyme that nevertheless retains its ability to specify product size in the absence of a PAZ domain. Its single RNase III domain dimerizes to cleave dsRNA; despite this similarity to bacterial enzymes of class 1, K. polysporus Dcr1 remains classified with other class 3 enzymes due to similarity in sequence and active site composition. A crystal structure and concomitant mechanistic studies revealed that Dcr1 dimers cleave dsRNA at precise intervals by abutting each other along the helix and measuring the product based on the distance occupied by the protein structure between the neighboring pairs of active sites, $23 \mathrm{nt}$ (Figure 3c) (90). This mechanism is in stark contrast to that of canonical Dicers, which measure from a dsRNA's terminus; $K$. polysporus Dcr1 begins at an arbitrary point within a dsRNA and works outwards in $23 \mathrm{nt}$ steps. Its mode of action is predicated on slow substrate release, which was indeed reported and is likely facilitated by one or both of the enzyme's two C-terminal dsRBDs (90).

The role of Dicer's helicase domain in RNA Recognition-The function of Dicer's helicase domain is best understood in the case of Drosophila Dicer-2. This enzyme is specialized to process siRNA precursors, which are longer perfectly-paired dsRNAs, while Dicer-1 handles the shorter and imperfect pre-miRNA hairpins (9). The canonical helicase domain of Dicer-2 consumes ATP to translocate the enzyme with respect to a long dsRNA, enabling processive generation of many siRNA duplexes from a single substrate helix (9). Furthermore, this domain facilitates processing of dsRNA substrates that lack the characteristic 2 nt $3^{\prime}$-terminal overhang (91). The divergent Dicer-1 helicase domain contains a Helicase $\mathrm{C}$ moiety but lacks the DExH/D lobe, providing an explanation for its inability to translocate along dsRNA. This modification does not completely abolish RNA binding: the domain has been implicated in recognition of the ssRNA loops characteristic of pre-miRNA hairpins thus contributing to the enzyme's specificity (85).

The parallel processing pathways for siRNA and miRNA are mirrored by a duplication of RNAi machinery in Drosophila, leading to differing, specialized helicase domains. But in humans a single Dicer is responsible for handling both types of precursor. This prompts the question: how does the single human Dicer recognize and process both types of substrate? Has the human helicase domain evolved greater adaptability in substrate specificity or has it experienced a partial loss of function? These questions remain to be fully resolved, but it seems to be the latter, since the human domain appears better adapted for the miRNA pathway. Unlike Drosophila Dicer-2, RNA processing for human Dicer is ATP-independent thus the helicase domain is unlikely to be involved in translocation of long dsRNA (97). Two biochemical reports implicate it in aiding miRNA processing, probably via binding of the pre-miRNA loop $(52,77)$.

A recent electron microscopic (EM) study elegantly employed extensive tagging and deletion of domains to deduce for the first time the global domain orientation of human Dicer (Figure 3d) (44). One surprising observation was the reorientation of the RNase III nuclease core with respect to the PAZ domain when comparing the structure of human Dicer to that of Giardia Dicer (54). This global reorganization likely stems from the $4 \mathrm{nt}$ (one-third of a dsRNA helical turn) length difference between the products of the two enzymes and the 
differing associated geometric requirements for cleavage (44). Similar rearrangements might be expected in Dicers producing products with other lengths. Data interpretation was bolstered by structure determination of the related helicase RIG-I, which provided a model that was readily positioned into the EM density for the helicase domain of human Dicer (41). The EM reconstruction of the elongated human Dicer revealed a helicase that is distal from the PAZ domain, with the paired RNase III active sites resting in between. This architecture is consistent with both known functions of the helicase domain. For premiRNAs, the PAZ domain will recognize the 2 nt overhang while the helicase is poised to recognize the hairpin's loop on the other end. For long dsRNA substrates, the helicase domain can feed the helix in towards the catalytic center for generation of multiple siRNAs. Accordingly, a concomitant EM reconstruction of the siRNA-specific Drosophila Dicer-2 revealed an architecture remarkably similar to that of human Dicer (44).

Dicer's interactions with other proteins-As part of the RLC, Dicer associates with an Argonaute protein and a dsRBP such as TRBP in humans. These interactions' mechanistic implications for the processes of strand selection and RISC loading will be discussed in a section below. The dsRBPs of RNAi tend comprise three dsRBDs connected by long, flexible linkers. The third such domain of TRPB has been shown to interact with a region of Dicer's helicase located between the DExD/H and Helicase C lobes (12). The interaction with Argonaute takes place between a portion of that protein's PIWI domain and a region within the N-terminal of Dicer's two RNase III domains $(71,80)$. The conserved Argonaute-interacting site on Dicer is present only in vertebrates, so Argonaute binding must be absent or manifested differently in other non-vertebrate RNAi systems (71).

A solution structure of Arabidopsis DCL4's DUF283 domain revealed a noncanonical dsRBD fold that was shown to interact with the second dsRBD of DRB4, a dsRBP homolog of TRBP (68). DRB4 contains two dsRBD domains but lacks a predicted third C-terminal dsRBD typically found in dsRBPs of RNAi pathways. This third dsRBD is commonly implicated in interaction with Dicer's helicase, so Arabidopsis appears to have evolved a different strategy for recognition between the two proteins. Indeed, the paralogous Arabidopsis protein pair DCL1 and DRB1 (also known as HYL1) similarly interact via their respective DUF283 and second dsRBP domains (68).

- dsRBPs

Dicing and RISC loading are aided to varying degrees by dsRBPs, which associate with a Dicer protein and typically comprise two or three dsRBDs. The dsRBD is a widespread domain that typically recognizes dsRNA based on its A-form helical shape with moderate to high affinity and in a sequence-nonspecific manner (16). These proteins typically contain a C-terminal non-canonical dsRBD that is dedicated to protein interaction instead of dsRNA binding. TRBP is the best characterized dsRBP of the human pathway and its 366 aa polypeptide bears three $\sim 70$ aa dsRNA-binding domains separated by two $\sim 70$ aa stretches of disordered linker (Figure 4a). This "beads on a string" domain architecture suggests that the protein may be involved in dsRNA handoff between Dicer and Argonaute, but detailed mechanistic evidence is scarce. RNAi pathway dsRBPs have been implicated in strand 
selection (8), stabilization of the miRNA-generating complex (66), and segregation of siRNAs into distinct pathways $(31,62)$.

Functional coupling between Dicers and dsRBPs-The multiplicity and diversity of dsRBPs impedes facile prediction of their roles in small-RNA pathways. Arabidopsis represents an extreme case, bearing five dsRBPs serially named DRB1-5. While these might be expected to generally pair off with the four Dicer-like proteins DCL1-4, such pairings are only observed for DRB1/DCL1, which produce miRNAs, and for DRB4/DCL4 which process siRNAs (11). DRB2, DRB3, and DRB5 seem to be somewhat redundant, while DCL2 and DCL3 appear to function unhindered in the absence of a dsRBP partner (11). Drosophila harbors a slightly more streamlined system in which Dicer-1 pairs with the PB isoform of dsRBP Loquacious (Loqs-PB) to process pre-miRNAs while Dicer-2 binds either R2D2 or Loqs-PD to process siRNAs of exogenous or endogenous origin, respectively (31).

The human system includes a solitary Dicer and two dsRBPs, TRBP and PACT, that each play poorly delineated roles in small RNA processing (46). While it is tempting to speculate that one human dsRBP is responsible for siRNA while the other tends to miRNA, such evidence has yet to be unearthed. Human Dicer's interaction with both TRBP and PACT is complicated by the fact that the two dsRBPs have each been reported to homodimerize and form heterodimers with each other (43). These dimerization interactions have been localized to the atypical yet conserved $\mathrm{C}$-terminal dsRBD of each protein, which also recognizes Dicer (12). Until it is determined if any of these binding interfaces are mutually exclusive, there are at least two plausible scenarios: Dicer can bind to TRBP or PACT interchangeably, or Dicer can bind TRBP and PACT simultaneously either independently or as a heterodimer.

Structure and RNA recognition of dsRBPs-Structural study of dsRBPs has been fruitful if not particularly illuminating regarding mechanism. Structures have been reported for the first two dsRBDs from TRBP, dsRBD1 and dsRBD2, with the latter bound to dsRNA (92). The RNA-bound structure adopts an $a / \beta$ sandwich that embodies the binding mode characteristic of a canonical dsRBP: the A-form helical geometry of dsRNA is recognized using protein loops and helices to bind the phosphate backbone at three points: two regions of minor groove surrounding a major groove along one face of the helix (Figure 4b) (16). RNA recognition is shape-based and not sequence-specific, as might be expected considering the requirements of the system. This mode of recognition's implications for strand selection will be discussed in a following section. Protein sequence differences subtly tune the dissociation constants of isolated dsRBD1 and dsRBD2 to 220 and $113 \mathrm{nM}$, respectively, while their collaborative affinity is $0.24 \mathrm{nM}$ in the context of the full-length protein (92). Similar variability in affinity is likely to be found on other RNAi pathway dsRBDs with little or no deviation from the canonical fold. No structural information is available for the non-canonical RNAi dsRBPs, which employ unknown means to recognize Dicer and/or other non-canonical dsRBPs.

\section{- Argonaute}

The functional lynchpin of all RNAi pathways is an Argonaute family protein bound to a strand of silencing RNA, which forms the minimal effector complex known as the RISC. 
The RISC performs cellular surveillance, silencing ssRNA sequences complementary to its bound guide strand. Argonaute proteins are found in bacteria, archaea, and eukaryotes. While the former two groups contain Argonauts of poorly-defined function (75), their eukaryotic counterparts have evolved into two clades with distinct functions. Proteins of the AGO clade mediate cytosolic gene silencing while bound to siRNAs or miRNAs, while PIWI clade proteins interact with piRNAs to manage mobile genetic elements of the germ line (28). Humans have four proteins of the former clade, dubbed Ago1-4. Of these four, only Ago2 exhibits "slicer" activity: the endonucleolytic cleavage of bound target ssRNA (35). Such activity is not required for gene silencing; human AGO proteins can accomplish regulation by binding a target, repressing its translation, and recruiting cellular machinery to induce deadenylation and mRNA decay (34).

Argonaute's key functions are recognition of guide strand termini, target cleavage, or recruitment of other proteins involved in silencing. Eukaryotic Argonaute proteins adopt a bilobal architecture, with each lobe containing either the N-terminal (or simply N) and PAZ domains or the MID and PIWI domains (Figure 5a,b). A series of illuminating crystal structures has provided the details of individual domains' functions in isolation initially, ultimately shedding light on how they work together in the context of a competent RISC complete with guide strand and target ssRNA. Via their similarity, structures of ternary complexes between RISC and target have shed light on the approximate the structure of the pre-RISC awaiting passenger strand dissociation.

Recognition of guide strand termini by Argonaute-The first Argonaute fragment structures revealed the PAZ domain to be responsible for recognizing $2 \mathrm{nt} 3^{\prime}$-overhangs, a finding with functional implications for PAZ-containing Dicer enzymes as well. The domain provides a pocket to accommodate $2 \mathrm{nt}$ of a $3^{\prime}$-terminus while making less extensive contacts with the $5^{\prime}$-terminus present in many dsRNAs of RNAi pathways (Figure $5 c$ ) (48, 53, 93). Side chains of the PAZ domain partake in extensive polar interactions with the bound RNA's buried phosphate group and sugar hydroxyls, though there are no specific contacts to the bound $2^{\prime}-\mathrm{OH}$ groups, consistent with RNAi being tolerant of such modifications $(10,53)$. The terminal nucleobase is partially buried in a hydrophobic cavity while the edges of the terminal two bases remain exposed to solvent, indicative of sequencenonspecific recognition (53).

In contrast to the indiscriminant $3^{\prime}$-terminal binding, $5^{\prime}$-termini tend to bear a particular nucleotide depending on the identity of the associated Argonaute protein (39). Crystal structures of eukaryotic Argonaute MID domains, some in complex with the four different nucleoside monophosphates mimicking the $5^{\prime}$ end of miRNAs, revealed specific contacts between a rigid loop in the MID domain and the nucleobase of UMP or AMP (Figure 5d) (5, 24). The electrostatic environment generated by this loop's functional groups is incompatible with CMP or GMP binding, a result that is consistent with NMR titration experiments showing that binding affinities of UMP $(0.12 \mathrm{mM})$ and AMP $(0.26 \mathrm{mM})$ are 30 fold lower than those measured for either CMP (3.6 mM) or GMP (3.3 mM) (24). The MID domain also bears two invariant lysines that recognize the $5^{\prime}$-terminal phosphate present in silencing RNAs (6). A crystal structure of an Archaeglobus fulgidus PIWI enzyme provided the first information on the conformation of a guide strand bound in a MID domain (65). 
The RNA is bound such that the $5^{\prime}$-terminal base is kinked and buried and unavailable for base pairing, as can be observed in the guide-bound structure of human Ago2 (Figure $5 b$ ) (47). This provides an explanation for previous biochemical observations that $5^{\prime}$-terminal base indentity is unimportant in target recognition (47).

Target recognition, slicer activity, and conformational changes-A series of structures characterizing full-length archaeal Argonautes has provided crucial details of the protein's catalytic mechanism, its interaction with a guide strand to form a competent RISC, and the orientation of ternary complexes formed in the presence of the passenger strand or a target ssRNA. A crystal structure of Argonaute from Pyrococcus furiosus revealed the PIWI domain to adopt an RNase H-like fold, implicating it as the catalytic domain and site of "slicer" activity (78). Similarly to the requirements for RNaseH activity, RISC-catalysed RNA cleavage requires divalent metal ions and yields a $5^{\prime}$ product, which has a free $3^{\prime}$ hydroxyl group, and a $3^{\prime}$ product, which carries a $5^{\prime}$ phosphate group. Crystal structures of Thermus thermophilus Argonaute bound to a DNA approximating the guide strand and an RNA target show a PIWI domain bearing a catalytic triad of aspartic acid residues that coordinate a pair of magnesium ions at an appropriate distance from the target strand's cleavage site (Figure 5f) (88). This catalytic triad DDX (where X is Asp or His) motif is present in catalytically active Argonautes and absent from those lacking slicer activity, and contrasts with the catalytic tetrad DEDD motif characteristic of RNase H enzymes (60). Curiously, the second magnesium ion could only be observed when crystallization conditions were adjusted from 50 to $80 \mathrm{mM} \mathrm{Mg}^{2+}$.

Despite the unnatural nature of the DNA guide present in the T. thermophilus structures, the guide:target duplex adopts the A-form geometry typical of a dsRNA double helix; A-form architecture is also adopted by a dsRNA duplex bound by A. fulgidus PIWI (64). When bound to a $12 \mathrm{nt}$ target, the $3^{\prime}$-terminus of the guide remains bound by the PAZ domain; in contrast, binding to a $15 \mathrm{nt}$ target induces release of the guide's end from the PAZ domain in order to accommodate the two strands' extension beyond a full turn (11 nt) of A-form helix (Figure 5e) (86). Concomitant slicing assays suggest that the guide strand's 3 '-terminus must be released from the PAZ domain for cleavage to take place, which is consistent with the structural observations: duplexes longer than a single turn can only be oriented correctly for target strand cleavage if the $3^{\prime}$-terminus of the guide is released. This finding supports the previously-proposed two state model and refutes fixed-end model that anticipated both termini of the guide strand remaining anchored during all stages of target recognition (88). Functional dispensability of $3^{\prime}$-terminus binding is further shown by mutations of the PAZ domain that have little effect in slicing assays, which contrasts with the loss of cleavage observed upon mutation of MID domain residues that recognize the $5^{\prime}$-terminus (89). Cleavage assays also demonstrate that bulges inserted in the guide's seed region prevent cleavage, whereas slicing can proceed in the presence of similar bulges in the same region of the target strand (87).

The conformation of the guide strand in the absence of target is of mechanistic significance. In crystal structures of guide-loaded Argonaute, the nucleic acid is bound in a central basic tract that spans the two lobes of the protein. The seed portion (positions 2-6) is typically well-ordered, while electron density has not been observed for nucleotides past position 10 , 
with the exception of a PAZ-bound terminal nucleotide $(18,60,72,89)$. Recent eukaryotic Argonaute structures bearing a traditional guide strand of RNA reveal a pre-ordered single helix in A-form geometry (Figure $5 b)(18,72)$. The thermodynamic repercussions of an ordered guide strand were explored in a series of isothermal titration calorimetry experiments in the context of $A$. fulgidus PIWI (63). The study shows that a guide strand held in a helical conformation can increase the affinity for target up to $\sim 300$-fold by decreasing the entropic cost that would otherwise be associated with ordering of the guide. This essentially increases the effective melting temperature and the propensity for binding between guide and target, which is of particular importance considering the prevalence of mismatches in the miRNA pathway.

Along with the reorientation of nucleic acid components upon RISC's binding of a target, the Argonaute protein has been observed or postulated to undergo its own rearrangements. When comparing T. thermophilus Argonaute bound to a $10 \mathrm{nt}$ versus a $21 \mathrm{nt}$ guide, moderate yet global reorientation of the protein takes place (89). The $10 \mathrm{nt}$ guide-bound conformation is likely similar to the unavailable free structure and the observed motion is presumed to be necessary to accommodate a full-length guide strand. The two lobes shift conformation again when a target is bound to the T. thermophilus protein, widening to allow formation of a double helix in the tract that previously housed only the guide strand (87). Still another protein conformation is sampled when the guide:target duplex becomes long enough to induce $3^{\prime}$-terminus release from the PAZ domain as discussed above; this involves a pivoting of the PAZ domain and a substantial shift of the PIWI domain loops dubbed L1 and L2 (Figure $5 g)(60,88)$. The significance of the L2 loop rearrangement became apparent upon determination of the structure of $K$. polysporus Argonaute, which bore a post-rearrangement conformation with a glutamate residue of L2 positioned appropriately to act as a fourth catalytic residue in conjunction with the aforementioned three aspartic acids (60). This observation can be extended to reveal mechanistic details of the T. thermophilus enzyme: upon sufficient base pairing between guide and target to release the $3^{\prime}$-terminus from the PAZ domain, L2 shifts and deposits the final moiety of a catalytic tetrad, apparently acting as a trigger for catalysis (Figure 5h). Thus catalytically-active Argonaute proteins indeed bear a DEDD (or DEDH in the case of human Ago2) catalytic tetrad as initially expected based on the homology between the PIWI domain and RNase H enzymes, and may undergo conformational change in response to target binding to permit selective catalytic activity (60).

The K. polysporus structure revealed an architecture allowing unobstructed formation of an extended guide:target duplex; this is in contrast to the T. Thermophilus enzyme, where the $\mathrm{N}$ domain would sterically clash with any such duplex longer than $16 \mathrm{bp}(60)$. The eukaryotic enzyme permits this by a rotation of the $\mathrm{N}$ domain. In the case of the human Ago2 structure, a potential steric clash is introduced: helix 7 abuts and slightly reorients the seventh nucleobase of the guide strand and its observed location would preclude target strand binding (Figure 5b) (72). Helix 7 has been proposed to facilitate passenger strand release and/or perform readout of miRNA target recognition that would be coupled to its necessary reorientation upon target binding (72). 
Interactions between Argonaute and other proteins-Human Argonaute's interaction with Dicer can be revisited in light of recent structural progress. As discussed above, the 58 aa "PIWI-box" was previously identified as the minimal portion of Argonaute sufficient for Dicer binding (80). It is now apparent that the PIWI-box constitutes a threestranded $\beta$-sheet from the middle of the PIWI domain. Interestingly, most of this sub-domain is occluded in the context of the full protein, leaving few reasonable options for intermolecular contacts with Dicer. However, if a $\sim 10$ aa stretch (bearing four proline residues) of Argonaute's N-terminus can be peeled away from the surface of the PIWI-box, it would reveal a much larger potential binding interface. Continued structural study will be necessary to verify the nature of an interaction that is probably vital for RISC loading.

Three of the four human Ago proteins lack slicing activity, yet they remain capable of inducing robust translational repression. This is brought about by an Argonaute's recruitment of glycine- and tryptophan-rich GW proteins that are components of the P body wherein mRNAs are degraded. GW182 is one such protein, known to contain multiple binding sites for Ago2 (81). The crystal structure of human Ago2 was crystallized in the presence of free tryptophan, revealing two pockets that each bind a tryptophan molecule primarily via hydrophobic interactions (Figure 5i) (72). Both the $24 \AA$ A spacing between pockets and the orientation of the carboxyl and amino groups of the bound amino acids are consistent with the geometry plausible for a pair of tryptophans in the context of a protein sequence with 8-14 aa between them, as is commonly found in GW proteins (72). This likely reveals the mechanism by which the PIWI domain of human Ago2 serves as an interaction platform for additional components of the RNAi machinery, as previously suspected (83).

\section{- GW:PABP interface}

Target-bound RISC binds GW proteins, which in turn form complexes localizing other cellular machinery to enact silencing. One such GW protein-induced recruitment is of poly(A) binding proteins (PABP). PABP binds an mRNA's $3^{\prime}$ poly(A) tail and recruits and PAIP1 and eIF4G to promote translation initiation via mRNA circularization (20). The competing PABP interaction with a GW protein likely inverts these effects, inhibiting translation initiation and inducing deadenylation, followed by message degradation. The interaction between the GW protein TNRC6C and polyadenylate-binding protein 1 (PABPC1) has been characterized, revealing recognition of a disordered region of a DUF domain from TNRC6 by the a-helical C-terminal domain of PABPC1 (Figure 6a) (37). The TNRC6C-interacting surface of PABPC1 overlaps with that used to bind PAIP1, suggesting the interactions are mutually exclusive. Concomitant assays in mammalian cell extracts demonstrated that mutations at the TNRC6C:PABPC1 interface impair mRNA deadenylation, proving evidence for this interaction's role in miRNA-mediated silencing (37).

\section{- C3PO}

Once pre-RISC has been assembled, Argonaute's slicing activity can promote passenger strand dissociation. This dissociation and subsequent RISC activation are inhibited when slicing is inhibited either by Argonaute mutations, via protecting modifications to the 
passenger strand, or in the case of Argonautes lacking catalytic activity $(57,58)$. RISC activation is promoted by the endonuclease $\mathrm{C} 3 \mathrm{PO}$, which has been shown to bind, nick, and subsequently degrade the passenger strand of pre-RISC (94). C3PO comprises a multimeric assembly of Trax and Translin protomers. Each protomer adopts the same fold, yet only Trax bears endonuclease activity. Recent crystal structures contain assemblies of Trax:Translin protomers in a ratio of $2: 6$ or 2:4 depending on the use of full-length or slightly truncated constructs (Figure $6 b)(82,94)$. Curiously, the observed C3PO complexes form hollow egg-shaped enclosures with an inner surface that bears the residues responsible for catalysis as well as an extensive positively-charged surface that likely binds ssRNA (82, 94). This architecture poses a mystery: how does the passenger strand substrate reach the inaccessible Trax active sites? It has been proposed that the substrate encounters the catalytic core either via a gap-generating conformational change of the multimeric complex, or by a partial dissociation of the assembly. Observations from native mass spectrometry of the C3PO complex support the latter possibility; diverse assemblies were detected, including Trax:Translin ratios of $6: 1,6: 2,5: 2,5: 3$, and 4:3 (82).

\section{FRONTIERS IN RNAi BIOPHYSICS}

\section{- Strand Selection}

Some of the most recalcitrant questions in RNAi pertain to the mechanisms of strand selection. While the sequence-level tendencies are well documented, it remains unclear how guide and passenger strand are distinguished on the molecular level (32). It is known that Argonaute's MID domain binds the $5^{\prime}$-terminal nucleobase selectively, generating a strong preference that varies depending on the Argonaute and can be detected empirically by deep sequencing of small RNAs $(32,39)$. It is also known that the RNAi duplex bearing the $5^{\prime}$ terminus participating in less thermodynamically stable base pairing is more likely to be loaded as the guide strand. The orientation of dicing does not determine guide strand identity $(61,67)$ and it has been reported that an RNAi dsRBP can act as an asymmetry sensor (17, 84 ) and/or as a functional bridge between Dicer and Argonaute (70). Interestingly, it has been difficult to assign the precise mechanisms responsible for the detection of thermodynamic asymmetry, probably because it is a dynamic process involving nuanced action by multiple proteins.

\section{- P-bodies}

P-bodies are cytoplasmic foci of RNA-driven silencing (reviewed in (42)), home to a host of proteins that cooperate to degrade an mRNA that has been targeted by RISC. These regions are defined by a sprawling network of protein:protein interactions, with a structural glimpse being provided by recent insight into the interfaces of GW proteins with PABP or Argonaute proteins $(37,72)$. Since the structures of many individual RNAi pathway proteins are now known, future structural biology efforts must focus on the binding sites between the players and the mechanisms by which they colocalize.

\section{- Kinetics of repression, decay, and RISC turnover}

An mRNA targeted by a non-slicing RISC is subject to translational repression, deadenylation, and exonucleolytic degradation, but the timing, mechanistic coupling, and 
relative importance of these processes have not been determined (reviewed in (14)). In the wake of cell-based studies implicating mRNA decay as the primary mode of silencing based on 12 and $32 \mathrm{~h}$ time points (29), two similar studies, each using multiple $2 \mathrm{~h}$ time points, demonstrated for the first time that translational repression precedes deadenylation and decay of a targeted miRNA $(1,15)$. These studies revealed the importance of kinetics in the silencing pathway. Impending studies will be especially illuminating if they are able to improve on the two-hour resolution used in recent experiments and/or track single-molecules instead of population kinetics.

Another unresolved kinetic question pertains to the lifetime of the RISC complex. While RISC-protected small RNAs were initially thought to have half-lives on the order of days, recent reports have shown these RNAs to be substrates for degradation by enzymes such as XRN2 (reviewed in (27)). The lifetime (and determinants thereof) of a given intact RISC will have profound repercussions for understanding miRNA function and successful design of siRNA-based therarapies, so this area of inquest is fertile ground for biophysical study.

\section{Acknowledgments}

This work is dedicated to Carolen Koleszar, former mentor to R.W. The authors are grateful to Mary Anne Kidwell, Ho Young Lee, and Cameron Noland for critical comments on the manuscript. We appreciate the contributions to Figure 3 made by Pick-Wei Lau and Ian MacRae. We thank Mark Glover and Stephen Chaulk for helpful communication. Support from the NIH to R.W. is greatfully acknowledged (F32GM096689). J.D. is an investigator of the Howard Hughes Medical Institute.

\section{Key Terms/Definitions}

These appear in boldface the first time each appears in the body of the text.

$\begin{array}{ll}\text { Argonaute } & \begin{array}{l}\text { A protein capable of binding short ssRNAs and, in some } \\ \text { cases, cleaving a bound complementary strand. }\end{array} \\ \text { Dicer } & \text { An endoribonuclease responsible for cleaving long } \\ \text { dsRNAs and/or pre-miRNAs to dsRNA duplexes of a } \\ \text { specific length. } \\ \text { The minimal RNA-induced silencing complex contains an } \\ \text { Argonaute protein bound to a guide strand; the effector of } \\ \text { silencing. } \\ \text { The RISC-loading complex contains at least Argonaute, } \\ \text { RLC } \\ \text { Dicer, and a dsRBP such as TRBP. } \\ \text { The nuclear protein complex of Drosha and DGCR8, } \\ \text { Microprocessor } \\ \text { responsible for cleavage of pri-miRNAs into pre-miRNAs. } \\ \text { A ssRNA of } ~ 20-30 \text { nt that base pairs with complementary } \\ \text { targets, thus providing the specificity of silencing } \\ \text { processes. }\end{array}$


Seed sequence
Positions $2-8$ of the guide stand, a region whose target complementarity is critical in determining the efficacy of silencing.

\section{Abbreviations}

$\begin{array}{ll}\text { RISC } & \text { RNA-induced silencing complex } \\ \text { RLC } & \text { RISC-loading complex } \\ \text { dsRBD } & \text { double-stranded RNA-binding domain } \\ \text { dsRBP } & \text { double-stranded RNA-binding protein } \\ \text { aa } & \text { amino acid } \\ \text { nt } & \text { nucleotide } \\ \text { ss } & \text { single-stranded } \\ \text { ds } & \text { double-stranded }\end{array}$

\section{LITERATURE CITED}

1. Bazzini AA, Lee MT, Giraldez AJ. Ribosome profiling shows that miR-430 reduces translation before causing mRNA decay in zebrafish. Science. 2012; 336(6078):233-237. [PubMed: 22422859]

2. Bellemer C, Bortolin-Cavaillé M-L, Schmidt U, Jensen SMR, Kjems J, Bertrand E, Cavaillé J. Microprocessor dynamics and interactions at endogenous imprinted C19MC microRNA genes. J. Cell. Sci. 2012; 125(Pt 11):2709-2720. [PubMed: 22393237]

3. Berezikov, E. Nat. Rev. Genet. Vol. 12. Nature Publishing Group; 2011. Evolution of microRNA diversity and regulation in animals; p. 846-860.

4. Bernstein E, Caudy AA, Hammond SM, Hannon GJ. Role for a bidentate ribonuclease in the initiation step of RNA interference. Nature. 2001; 409(6818):363-366. [PubMed: 11201747]

5. Boland A, Huntzinger E, Schmidt S, Izaurralde E, Weichenrieder O. Crystal structure of the MIDPIWI lobe of a eukaryotic Argonaute protein. Proc. Natl. Acad. Sci. U.S.A. 2011; 108(26):1046610471. [PubMed: 21646546]

6. Boland A, Tritschler F, Heimstädt S, Izaurralde E, Weichenrieder O. Crystal structure and ligand binding of the MID domain of a eukaryotic Argonaute protein. EMBO Rep. 2010; 11(7):522-527. [PubMed: 20539312]

7. Carthew RW, Sontheimer EJ. Origins and Mechanisms of miRNAs and siRNAs. Cell. 2009; 136(4): 642-655. [PubMed: 19239886]

8. Castanotto D, Sakurai K, Lingeman R, Li H, Shively L, Aagaard L, Soifer H, Gatignol A, Riggs A, Rossi JJ. Combinatorial delivery of small interfering RNAs reduces RNAi efficacy by selective incorporation into RISC. Nucleic Acids Research. 2007; 35(15):5154-5164. [PubMed: 17660190]

9. Cenik, ES., Fukunaga, R., Lu, G., Dutcher, R., Wang, Y., Hall, TMT., Zamore, PD. Molecular Cell. Elsevier Inc; 2011. Phosphate and R2D2 Restrict the Substrate Specificity of Dicer-2, an ATPDriven Ribonuclease; p. 1-13.

10. Chiu Y-L, Rana TM. siRNA function in RNAi: a chemical modification analysis. RNA. 2003; 9(9): 1034-1048. [PubMed: 12923253]

11. Curtin SJ, Watson JM, Smith NA, Eamens AL, Blanchard CL, Waterhouse PM. The roles of plant dsRNA-binding proteins in RNAi-like pathways. FEBS Letters. 2008; 582(18):2753-2760.

[PubMed: 18625233] 
12. Daniels SM, Melendez-Peña CE, Scarborough RJ, Daher A, Christensen HS, Far El M, Purcell DF, Lainé S, Gatignol A. Characterization of the TRBP domain required for Dicer interaction and function in RNA interference. BMC Mol Biol. 2009; 10(1):38. [PubMed: 19422693]

13. Davidson, BL., McCray, PB. Nat. Rev. Genet. Vol. 12. Nature Publishing Group; 2011. Current prospects for RNA interference-based therapies; p. 329-340.

14. Djuranovic S, Nahvi A, Green R. A Parsimonious Model for Gene Regulation by miRNAs. Science. 2011; 331(6017):550-553. [PubMed: 21292970]

15. Djuranovic S, Nahvi A, Green R. miRNA-mediated gene silencing by translational repression followed by mRNA deadenylation and decay. Science. 2012; 336(6078):237-240. [PubMed: 22499947]

16. Doyle M, Jantsch MF. New and old roles of the double-stranded RNA-binding domain. Journal of Structural Biology. 2002; 140(1-3):147-153. [PubMed: 12490163]

17. Eamens AL, Smith NA, Curtin SJ, Wang M-B, Waterhouse PM. The Arabidopsis thaliana doublestranded RNA binding protein DRB1 directs guide strand selection from microRNA duplexes. RNA. 2009; 15(12):2219-2235. [PubMed: 19861421]

18. Elkayam, E., Kuhn, C-D., Tocilj, A., Haase, AD., Greene, EM., Hannon, GJ., Joshua-Tor, L. Cell. Elsevier Inc; 2012. The Structure of Human Argonaute-2 in Complex with miR-20a; p. 1-11.

19. Eulalio A, Huntzinger E, Izaurralde E. GW182 interaction with Argonaute is essential for miRNAmediated translational repression and mRNA decay. Nature Structural \& Molecular Biology. 2008; 15(4):346-353.

20. Fabian MR, Sonenberg N. The mechanics of miRNA-mediated gene silencing: a look under the hood of miRISC. Nature Structural \& Molecular Biology. 2012; 19(6):586-593.

21. Fabian MR, Sonenberg N, Filipowicz W. Regulation of mRNA translation and stability by microRNAs. Annu. Rev. Biochem. 2010; 79:351-379. [PubMed: 20533884]

22. Faller M, Toso D, Matsunaga M, Atanasov I, Senturia R, Chen Y, Zhou ZH, Guo F. DGCR8 recognizes primary transcripts of microRNAs through highly cooperative binding and formation of higher-order structures. RNA. 2010; 16(8):1570-1583. [PubMed: 20558544]

23. Farrukh. MicroRNA: Biogenesis, Function, and Role in Cancer. 2010:1-25.

24. Frank F, Sonenberg N, Nagar B. Structural basis for 5'-nucleotide base-specific recognition of guide RNA by human AGO2. Nature. 2010; 465(7299):818-822. [PubMed: 20505670]

25. Gan J, Tropea JE, Austin BP, Court DL, Waugh DS, Ji X. Structural insight into the mechanism of double-stranded RNA processing by ribonuclease III. Cell. 2006; 124(2):355-366. [PubMed: 16439209]

26. Gregory RI, Yan K-P, Amuthan G, Chendrimada T, Doratotaj B, Cooch N, Shiekhattar R. The Microprocessor complex mediates the genesis of microRNAs. Nature. 2004; 432(7014):235-240. [PubMed: 15531877]

27. Großhans, H., Chatterjee, S. Regulation of microRNAs. Springer; 2011. MicroRNAses and the regulated degradation of mature animal miRNAs; p. 140-155.

28. Gunawardane LS, Saito K, Nishida KM, Miyoshi K, Kawamura Y, Nagami T, Siomi H, Siomi MC. A slicer-mediated mechanism for repeat-associated siRNA 5' end formation in Drosophila. Science. 2007; 315(5818):1587-1590. [PubMed: 17322028]

29. Guo H, Ingolia NT, Weissman JS, Bartel DP. Mammalian microRNAs predominantly act to decrease target mRNA levels. Nature. 2010; 466(7308):835-840. [PubMed: 20703300]

30. Han J, Lee Y, Yeom K-H, Nam J-W, Heo I, Rhee J-K, Sohn SY, Cho Y, Zhang B-T, Kim VN. Molecular Basis for the Recognition of Primary microRNAs by the Drosha-DGCR8 Complex. Cell. 2006; 125(5):887-901. [PubMed: 16751099]

31. Hartig JV, Förstemann K. Loqs-PD and R2D2 define independent pathways for RISC generation in Drosophila. Nucleic Acids Research. 2011; 39(9):3836-3851. [PubMed: 21245036]

32. Hu H, Yan Z, Xu Y, Hu H, Menzel C, Zhou Y, Chen W, Khaitovich P. Sequence features associated with microRNA strand selection in humans and flies. BMC Genomics. 2009; 10(1):413. [PubMed: 19732433]

33. Huang Y, Ji L, Huang Q, Vassylyev DG, Chen X, Ma J-B. Structural insights into mechanisms of the small RNA methyltransferase HEN1. Nature. 2009; 461(7265):823-827. [PubMed: 19812675] 
34. Jackson RJ, Standart N. How do microRNAs regulate gene expression? Sci. STKE. 2007; 2007(367):re1. [PubMed: 17200520]

35. Janowski BA, Huffman KE, Schwartz JC, Ram R, Nordsell R, Shames DS, Minna JD, Corey DR. Involvement of AGO1 and AGO2 in mammalian transcriptional silencing. Nature Structural \& Molecular Biology. 2006; 13(9):787-792.

36. Jinek M, Doudna JA. A three-dimensional view of the molecular machinery of RNA interference. Nature. 2009; 457(7228):405-412. [PubMed: 19158786]

37. Jinek M, Fabian MR, Coyle SM, Sonenberg N, Doudna JA. Structural insights into the human GW182-PABC interaction in microRNA-mediated deadenylation. Nature Structural \& Molecular Biology. 2010; 17(2):238-240.

38. Kataoka N, Fujita M, Ohno M. Functional association of the Microprocessor complex with the spliceosome. Mol. Cell. Biol. 2009; 29(12):3243-3254. [PubMed: 19349299]

39. Kawamata, T., Tomari, Y. Trends in Biochemical Sciences. Vol. 35. Elsevier Ltd; 2010. Making RISC; p. 368-376.

40. Kim Y-K, Kim VN. Processing of intronic microRNAs. EMBO J. 2007; 26(3):775-783. [PubMed: 17255951]

41. Kowalinski E, Lunardi T, McCarthy AA, Louber J, Brunel J, Grigorov B, Gerlier D, Cusack S. Structural basis for the activation of innate immune pattern-recognition receptor RIG-I by viral RNA. Cell. 2011; 147(2):423-435. [PubMed: 22000019]

42. Kulkarni M, Ozgur S, Stoecklin G. On track with P-bodies. Biochem. Soc. Trans. 2010; 38(1):242. [PubMed: 20074068]

43. Laraki G, Clerzius G, Daher A, Melendez-Peña C, Daniels S, Gatignol A. Interactions between the double-stranded RNA-binding proteins TRBP and PACT define the Medipal domain that mediates protein-protein interactions. RNA Biol. 2008; 5(2):92-103. [PubMed: 18421256]

44. Lau, P-W., Guiley, KZ., De, N., Potter, CS., Carragher, B., MacRae, IJ. Nature Structural \& Molecular Biology. Vol. 19. Nature Publishing Group; 2012. The molecular architecture of human Dicer; p. 436-440.

45. Lee Y, Ahn C, Han J, Choi H, Kim J, Yim J, Lee J, et al. The nuclear RNase III Drosha initiates microRNA processing. Nature. 2003; 425(6956):415-419. [PubMed: 14508493]

46. Lee Y, Hur I, Park S-Y, Kim Y-K, Suh MR, Kim VN. The role of PACT in the RNA silencing pathway. EMBO J. 2006; 25(3):522-532. [PubMed: 16424907]

47. Lewis BP, Burge CB, Bartel DP. Conserved seed pairing, often flanked by adenosines, indicates that thousands of human genes are microRNA targets. Cell. 2005; 120(1):15-20. [PubMed: 15652477]

48. Lingel A, Simon B, Izaurralde E, Sattler M. Nucleic acid $3^{\prime}$-end recognition by the Argonaute2 PAZ domain. Nature Structural \& Molecular Biology. 2004; 11(6):576-577.

49. Lu M, Zhang Q, Deng M, Miao J, Guo Y, Gao W, Cui Q. An analysis of human microRNA and disease associations. PLoS ONE. 2008; 3(10):e3420. [PubMed: 18923704]

50. Lund E, Dahlberg JE. Substrate selectivity of exportin 5 and Dicer in the biogenesis of microRNAs. Cold Spring Harb. Symp. Quant. Biol. 2006; 71:59-66. [PubMed: 17381281]

51. Ma E, MacRae IJ, Kirsch JF, Doudna JA. Autoinhibition of Human Dicer by Its Internal Helicase Domain. Journal of Molecular Biology. 2008; 380(1):237-243. [PubMed: 18508075]

52. Ma E, Zhou K, Kidwell MA, Doudna JA. Coordinated Activities of Human Dicer Domains in Regulatory RNA Processing. Journal of Molecular Biology. 2012

53. Ma J-B, Ye K, Patel DJ. Structural basis for overhang-specific small interfering RNA recognition by the PAZ domain. Nature. 2004; 429(6989):318-322. [PubMed: 15152257]

54. MacRae IJ. Structural Basis for Double-Stranded RNA Processing by Dicer. Science. 2006; 311(5758):195-198. [PubMed: 16410517]

55. MacRae IJ, Doudna JA. Ribonuclease revisited: structural insights into ribonuclease III family enzymes. Curr. Opin. Struct. Biol. 2007; 17(1):138-145. [PubMed: 17194582]

56. MacRae IJ, Ma E, Zhou M, Robinson CV, Doudna JA. In vitro reconstitution of the human RISCloading complex. Proc. Natl. Acad. Sci. U.S.A. 2008; 105(2):512-517. [PubMed: 18178619] 
57. Maiti M, Lee H-C, Liu Y. QIP, a putative exonuclease, interacts with the Neurospora Argonaute protein and facilitates conversion of duplex siRNA into single strands. Genes \& Development. 2007; 21(5):590-600. [PubMed: 17311884]

58. Matranga C, Tomari Y, Shin C, Bartel DP, Zamore PD. Passenger-strand cleavage facilitates assembly of siRNA into Ago2-containing RNAi enzyme complexes. Cell. 2005; 123(4):607-620. [PubMed: 16271386]

59. Mueller GA, Miller MT, Derose EF, Ghosh M, London RE, Hall TMT. Solution structure of the Drosha double-stranded RNA-binding domain. Silence. 2010; 1(1):2. [PubMed: 20226070]

60. Nakanishi, K., Weinberg, DE., Bartel, DP., Patel, DJ. Nature. Nature Publishing Group; 2012. Structure of yeast Argonaute with guide RNA; p. 1-9.

61. Noland, CL., Ma, E., Doudna, JA. Molecular Cell. Vol. 43. Elsevier Inc; 2011. siRNA Repositioning for Guide Strand Selection by Human Dicer Complexes; p. 110-121.

62. Okamura K, Robine N, Liu Y, Liu Q, Lai EC. R2D2 organizes small regulatory RNA pathways in Drosophila. Mol. Cell. Biol. 2011; 31(4):884-896. [PubMed: 21135122]

63. Parker, JS., Parizotto, EA., Wang, M., Roe, SM., Barford, D. Molecular Cell. Vol. 33. Elsevier Inc; 2009. Enhancement of the Seed-Target Recognition Step in RNA Silencing by a PIWI/MID Domain Protein; p. 204-214.

64. Parker JS, Roe SM, Barford D. Crystal structure of a PIWI protein suggests mechanisms for siRNA recognition and slicer activity. EMBO J. 2004; 23(24):4727-4737. [PubMed: 15565169]

65. Parker JS, Roe SM, Barford D. Structural insights into mRNA recognition from a PIWI domainsiRNA guide complex. Nature. 2005; 434(7033):663-666. [PubMed: 15800628]

66. Paroo, Z., Ye, X., Chen, S., Liu, Q. Cell. Vol. 139. Elsevier Ltd; 2009. Phosphorylation of the Human MicroRNA-Generating Complex Mediates MAPK/Erk Signaling; p. 112-122.

67. Preall JB, He Z, Gorra JM, Sontheimer EJ. Short interfering RNA strand selection is independent of dsRNA processing polarity during RNAi in Drosophila. Curr. Biol. 2006; 16(5):530-535. [PubMed: 16527750]

68. Qin H, Chen F, Huan X, Machida S, Song J, Yuan YA. Structure of the Arabidopsis thaliana DCL4 DUF283 domain reveals a noncanonical double-stranded RNA-binding fold for protein-protein interaction. RNA. 2010; 16(3):474-481. [PubMed: 20106953]

69. Saini HK, Griffiths-Jones S, Enright AJ. Genomic analysis of human microRNA transcripts. Proc. Natl. Acad. Sci. U.S.A. 2007; 104(45):17719-17724. [PubMed: 17965236]

70. Sakurai K, Amarzguioui M, Kim DH, Alluin J, Heale B, Song MS, Gatignol A, Behlke MA, Rossi JJ. A role for human Dicer in pre-RISC loading of siRNAs. Nucleic Acids Research. 2011; 39(4): 1510-1525. [PubMed: 20972213]

71. Sasaki T, Shimizu N. Evolutionary conservation of a unique amino acid sequence in human DICER protein essential for binding to Argonaute family proteins. Gene. 2007; 396(2):312-320. [PubMed: 17482383]

72. Schirle NT, MacRae IJ. The crystal structure of human Argonaute2. Science. 2012; 336(6084): 1037-1040. [PubMed: 22539551]

73. Schwarz DS, Hutvágner G, Du T, Xu Z, Aronin N, Zamore PD. Asymmetry in the assembly of the RNAi enzyme complex. Cell. 2003; 115(2):199-208. [PubMed: 14567917]

74. Senturia R, Faller M, Yin S, Loo JA, Cascio D, Sawaya MR, Hwang D, Clubb RT, Guo F. Structure of the dimerization domain of DiGeorge critical region 8. Protein Sci. 2010; 19(7):1354-1365. [PubMed: 20506313]

75. Shabalina SA, Koonin EV. Origins and evolution of eukaryotic RNA interference. Trends Ecol. Evol. (Amst.). 2008; 23(10):578-587. [PubMed: 18715673]

76. Sohn SY, Bae WJ, Kim JJ, Yeom K-H, Kim VN, Cho Y. Crystal structure of human DGCR8 core. Nature Structural \& Molecular Biology. 2007; 14(9):847-853.

77. Soifer HS, Sano M, Sakurai K, Chomchan P, Saetrom P, Sherman MA, Collingwood MA, Behlke MA, Rossi JJ. A role for the Dicer helicase domain in the processing of thermodynamically unstable hairpin RNAs. Nucleic Acids Research. 2008; 36(20):6511-6522. [PubMed: 18927112]

78. Song J-J, Smith SK, Hannon GJ, Joshua-Tor L. Crystal structure of Argonaute and its implications for RISC slicer activity. Science. 2004; 305(5689):1434-1437. [PubMed: 15284453] 
79. Sun W, Pertzev A, Nicholson AW. Catalytic mechanism of Escherichia coli ribonuclease III: kinetic and inhibitor evidence for the involvement of two magnesium ions in RNA phosphodiester hydrolysis. Nucleic Acids Research. 2005; 33(3):807-815. [PubMed: 15699182]

80. Tahbaz N, Kolb FA, Zhang H, Jaronczyk K, Filipowicz W, Hobman TC. Characterization of the interactions between mammalian PAZ PIWI domain proteins and Dicer. EMBO Rep. 2004; 5(2): 189-194. [PubMed: 14749716]

81. Takimoto K, Wakiyama M, Yokoyama S. Mammalian GW182 contains multiple Argonautebinding sites and functions in microRNA-mediated translational repression. RNA. 2009; 15(6): 1078-1089. [PubMed: 19398495]

82. Tian Y, Simanshu DK, Ascano M, Diaz-Avalos R, Park AY, Juranek SA, Rice WJ, et al. Multimeric assembly and biochemical characterization of the Trax-translin endonuclease complex. Nature Structural \& Molecular Biology. 2011; 18(6):658-664.

83. Till S, Lejeune E, Thermann R, Bortfeld M, Hothorn M, Enderle D, Heinrich C, Hentze MW, Ladurner AG. A conserved motif in Argonaute-interacting proteins mediates functional interactions through the Argonaute PIWI domain. Nat Struct Mol Biol. 2007; 14(10):897-903. [PubMed: 17891150]

84. Tomari Y. A Protein Sensor for siRNA Asymmetry. Science. 2004; 306(5700):1377-1380. [PubMed: 15550672]

85. Tsutsumi A, Kawamata T, Izumi N, Seitz H, Tomari Y. Recognition of the pre-miRNA structure by Drosophila Dicer-1. Nature Structural \& Molecular Biology. 2011; 18(10):1153-1158.

86. Wang, H-W., Noland, C., Siridechadilok, B., Taylor, DW., Ma, E., Felderer, K., Doudna, JA., Nogales, E. Nature Structural \& Molecular Biology. Vol. 16. Nature Publishing Group; 2009. Structural insights into RNA processing by the human RISC-loading complex; p. 1148-1153.

87. Wang Y, Juranek S, Li H, Sheng G, Tuschl T, Patel DJ. Structure of an argonaute silencing complex with a seed-containing guide DNA and target RNA duplex. Nature. 2008; 456(7224): 921-926. [PubMed: 19092929]

88. Wang Y, Juranek S, Li H, Sheng G, Wardle GS, Tuschl T, Patel DJ. Nucleation, propagation and cleavage of target RNAs in Ago silencing complexes. Nature. 2009; 461(7265):754-761. [PubMed: 19812667]

89. Wang Y, Sheng G, Juranek S, Tuschl T, Patel DJ. Structure of the guide-strand-containing argonaute silencing complex. Nature. 2008; 456(7219):209-213. [PubMed: 18754009]

90. Weinberg, DE., Nakanishi, K., Patel, DJ., Bartel, DP. Cell. Vol. 146. Elsevier Inc; 2011. The Inside-Out Mechanism of Dicers from Budding Yeasts; p. 262-276.

91. Welker NC, Maity TS, Ye X, Aruscavage PJ, Krauchuk AA, Liu Q, Bass BL. Dicer's helicase domain discriminates dsRNA termini to promote an altered reaction mode. Molecular Cell. 2011; 41(5):589-599. [PubMed: 21362554]

92. Yamashita S, Nagata T, Kawazoe M, Takemoto C, Kigawa T, Güntert P, Kobayashi N, et al. Structures of the first and second double-stranded RNA-binding domains of human TAR RNAbinding protein. Protein Science. 2010; 20(1):118-130.

93. Yan KS, Yan S, Farooq A, Han A, Zeng L, Zhou M-M. Structure and conserved RNA binding of the PAZ domain. Nature. 2003; 426(6965):468-474. [PubMed: 14615802]

94. Ye, X., Huang, N., Liu, Y., Paroo, Z., Huerta, C., Li, P., Chen, S., Liu, Q., Zhang, H. Nature Structural \& Molecular Biology. Vol. 18. Nature Publishing Group; 2011. Structure of C3PO and mechanism of human RISC activation; p. 650-657.

95. Zeng Y, Cullen BR. Efficient processing of primary microRNA hairpins by Drosha requires flanking nonstructured RNA sequences. J. Biol. Chem. 2005; 280(30):27595-27603. [PubMed: 15932881]

96. Zeng Y, Yi R, Cullen BR. Recognition and cleavage of primary microRNA precursors by the nuclear processing enzyme Drosha. EMBO J. 2005; 24(1):138-148. [PubMed: 15565168]

97. Zhang H, Kolb FA, Brondani V, Billy E, Filipowicz W. Human Dicer preferentially cleaves dsRNAs at their termini without a requirement for ATP. EMBO J. 2002; 21(21):5875-5885. [PubMed: 12411505]

98. Zou J, Chang M, Nie P, Secombes CJ. Origin and evolution of the RIG-I like RNA helicase gene family. BMC Evol. Biol. 2009; 9:85. [PubMed: 19400936] 


\section{SUMMARY POINTS}

1. The central macromolecules and interactions of the RNAi pathway have been identified, with increasing mechanistic insight being provided by structural models.

2. A wealth of Argonaute structures has revealed the protein:RNA interactions central to RNA interference.

3. The molecular architecture of Dicer is known, shedding light on how different Dicers produce products of varying lengths. 


\section{FUTURE ISSUES}

1. What is the architecture of the microprocessor complex and how does it facilitate recognition of the stem-ssRNA junction?

2. The structure of human Dicer lacks a high-resolution structure, and there are no RNA-bound Dicer structures available for any organism.

3. How does the RISC loading complex perform the subtle task of strand selection?

4. What are the structural details of key protein:protein interfaces such as Argonaute:GW-protein, Argonaute:Dicer, Dicer:dsRBP, and Drosha:DGCR8?

5. What are the spatial and kinetic properties of silencing processes downstream of RISC assembly? 


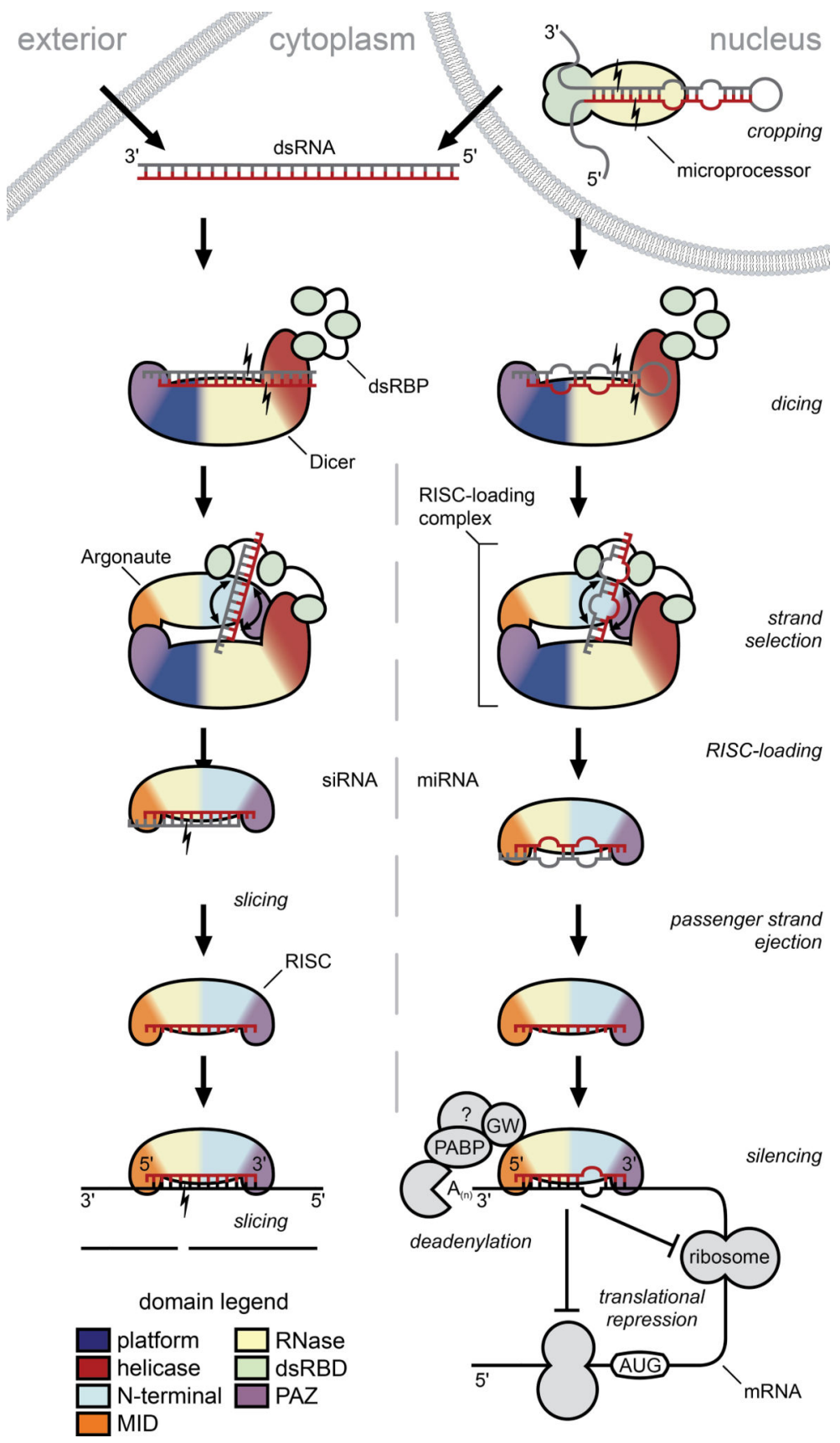

Figure 1.

The siRNA (left) and miRNA (right) pathways of RNA interference. Protein domain architecture is approximated in the cartoons here, and domain coloring is maintained in subsequent figures. For clarity, one dsRBD has been omitted from each of the Dicer and microprocessor cartoons. 

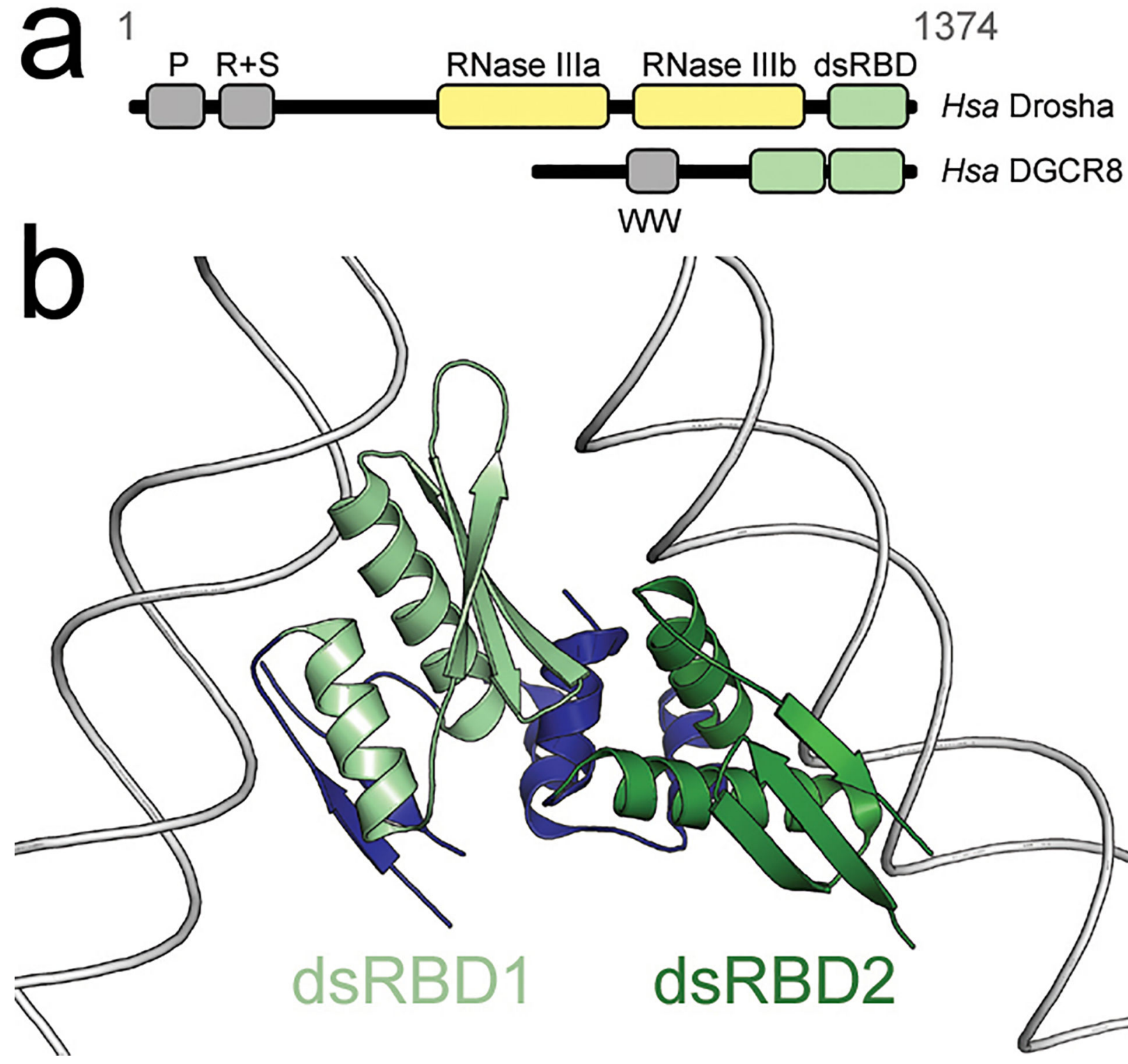


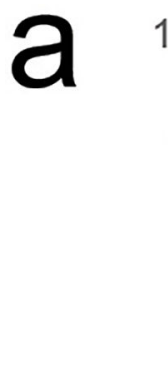

1

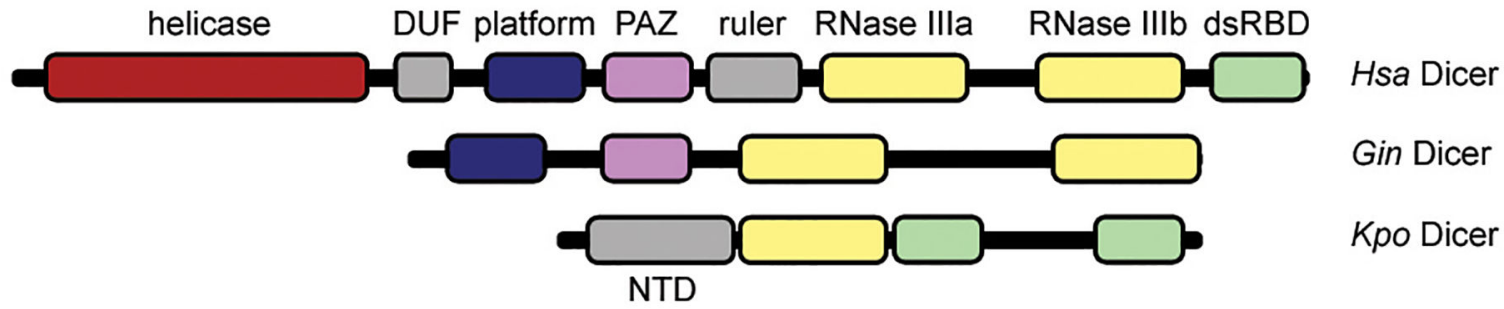

b

\section{RNase IIIa}

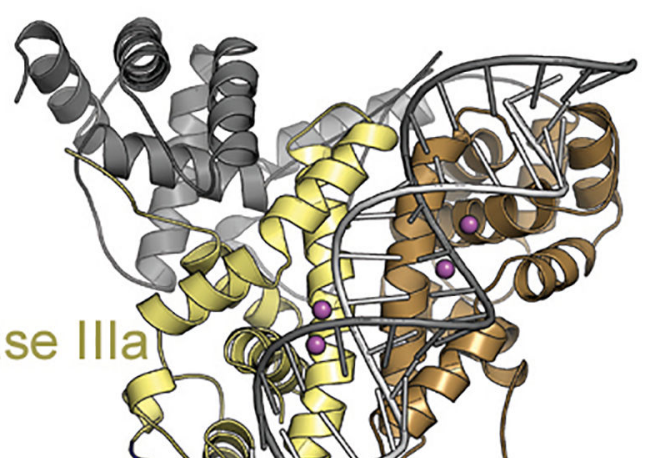

C
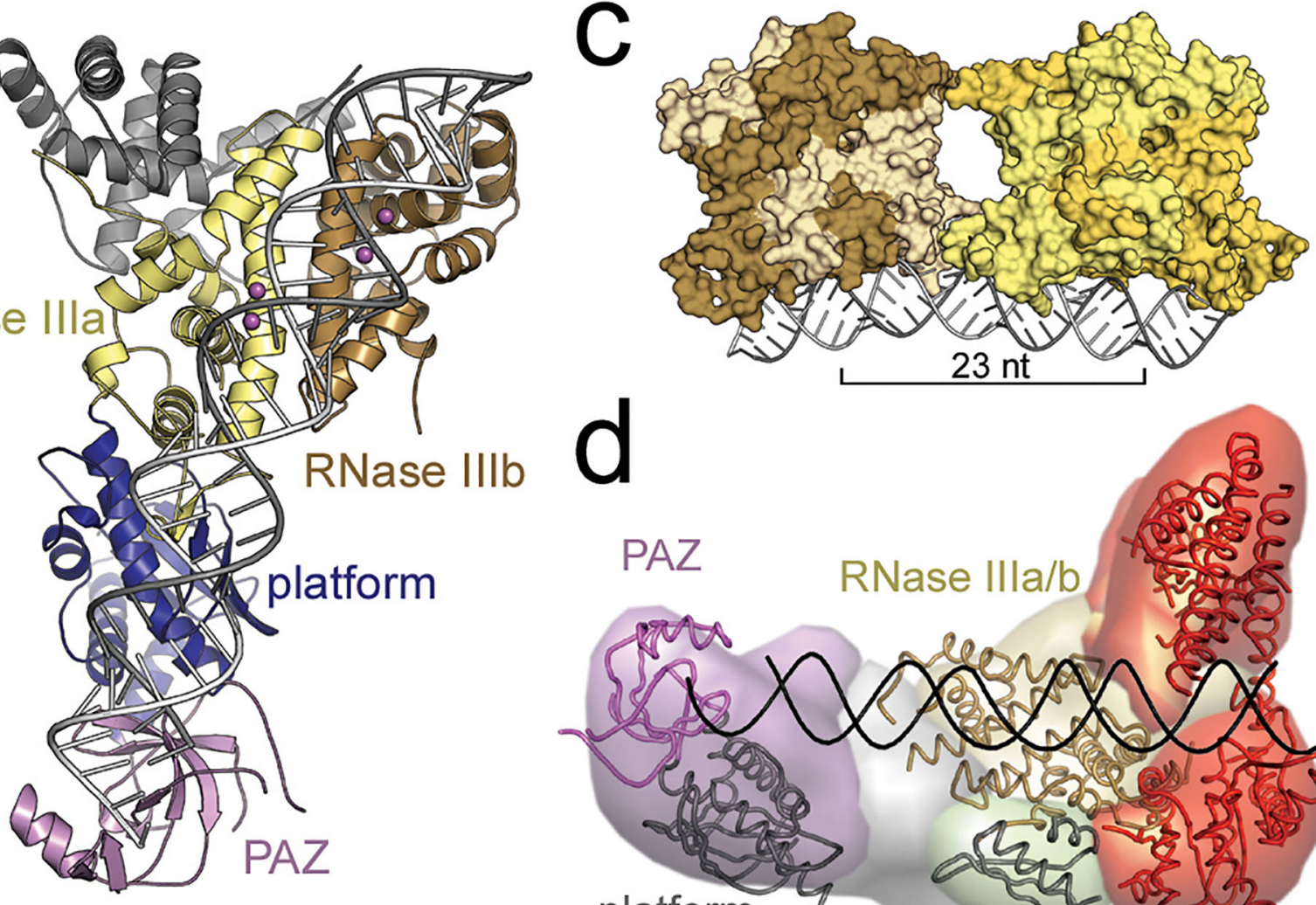

d
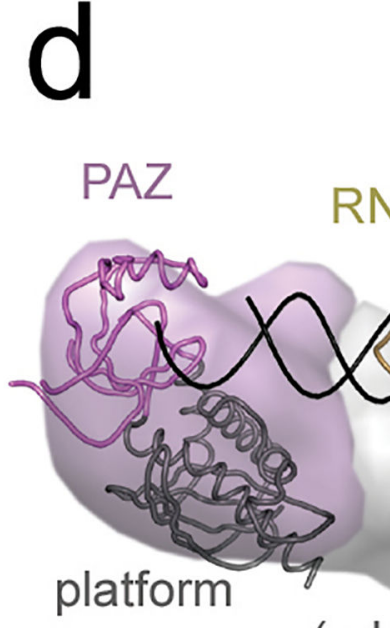

RNase IIIa/b

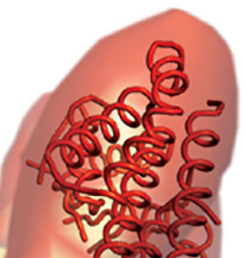

(ruler)

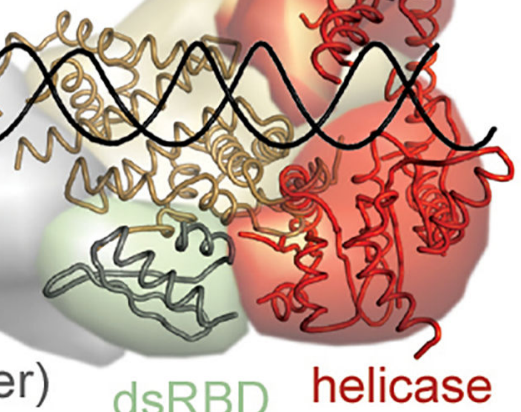

Figure 3.

The Dicer family's diverse architecture. (a) Domain structures of Dicer enzymes from humans, Giardia intestinalis (Gin), or K. polysporus (Kpo). The domain of unknown function (DUF) and anticipated ruler domain are indicated for the human enzyme. $K$. polysporus Dicer bears a single RNase III domain and an N-terminal domain (NTD) that mediates dimerization. (b) Dicer's measurement and cleavage of pre-miRNA as illustrated by the $G$. intestinalis crystal structure (PDB ID: 2FFL). Purple spheres represent erbium atoms present in the crystal, which reflect the position of the $\mathrm{Mg}^{2+}$ ions critical to RNase III enzyme catalysis. In this model, a dsRNA's 2 nt 3 '-terminal overhang is docked into Dicer's PAZ domain, orienting it for two cleavage events $65 \AA$ away at the active site, generating a 25 nt duplex. (c) The inside-out mechanism of $K$. polysporus Dicer (PDB ID: 3RV0). This enzyme lacks a PAZ domain and uses neighboring molecules to measure its product. This model depicts two homodimers of the enzyme, each bearing a single RNase III domain, 
contacting each other to measure a $23 \mathrm{nt}$ product. The resulting dsRNA will originate from the center of the substrate duplex, in contrast to the end-derived products generated by PAZcontaining Dicers. (d) The global architecture of human Dicer. Homologous domains have been docked into a segmented EM map (PDB IDs: 4A36, 2KOU, 2FFL, and 3C4T). The helicase domain resembles a clamp and is optimally oriented to guide an incoming dsRNA substrate (speculatively modeled here in black) towards the RNase IIIa/b active center and PAZ domain. Relative to the $G$. intestinalis enzyme, a ruler domain is inserted and the PAZ domain is reoriented with respect to the RNase III catalytic center. These changes likely relate to the fact that human Dicer products are 4 nt shorter than those of $G$. intestinalis. 
a

1 dsRBD1 dsRBD2 dsRBD3 345 Hsa TRBP b

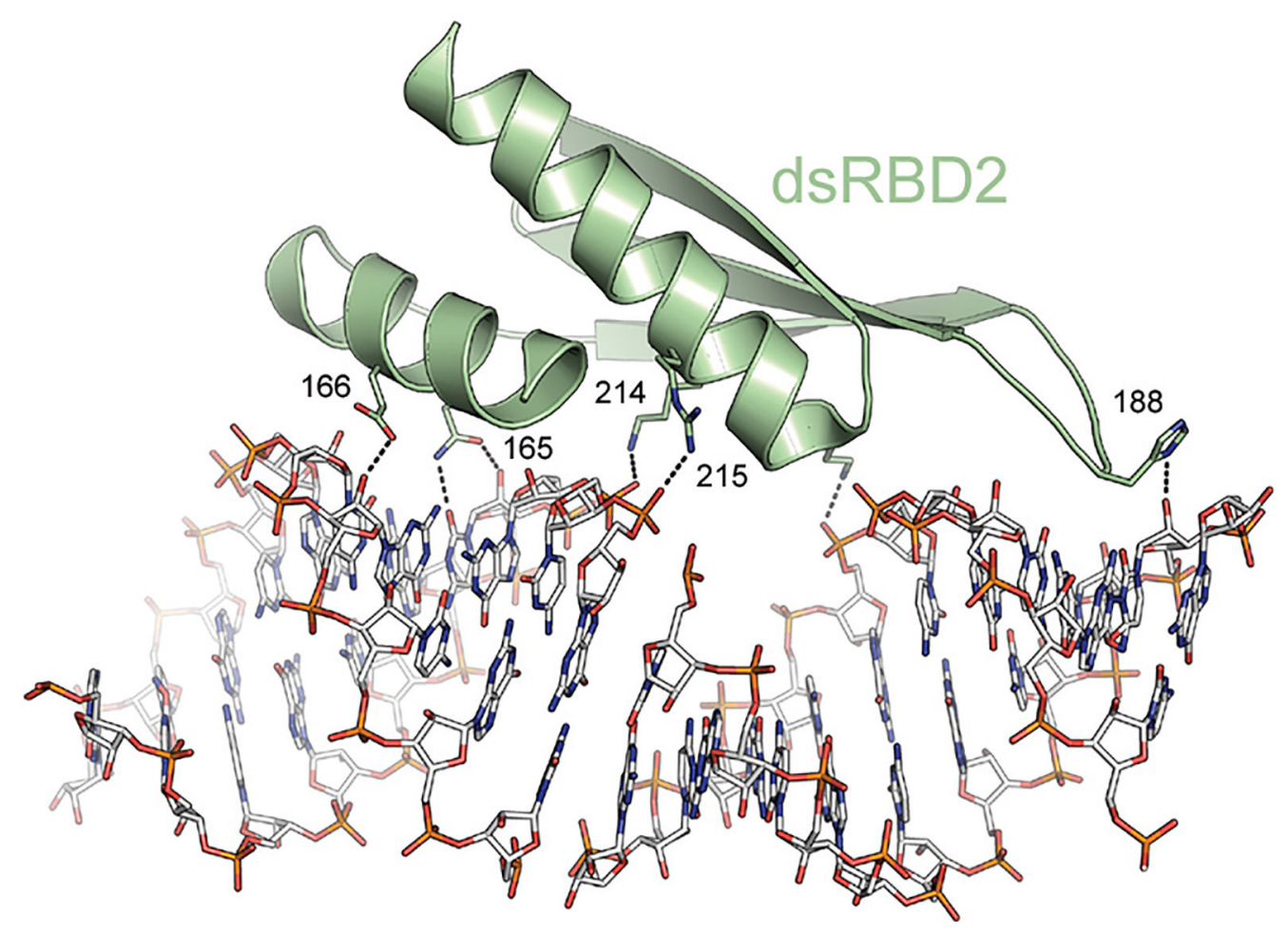

Figure 4.

The structure of dsRNA-binding proteins. (a) The domain structure of human TRPB, a typical dsRBP of the RNAi pathway. The well-folded dsRBDs are separated by flexible $\sim 70$ aa linkers, lending the protein a "beads on a string" quality. The first two domains bind dsRNA while the third instead binds to Dicer. (b) The crystal structure of TRBP's second dsRBD in complex with dsRNA (PDB ID: 3ADL). The protein uses three interfaces to recognize successive portions of minor, major, and minor groove along one face of a helix. 


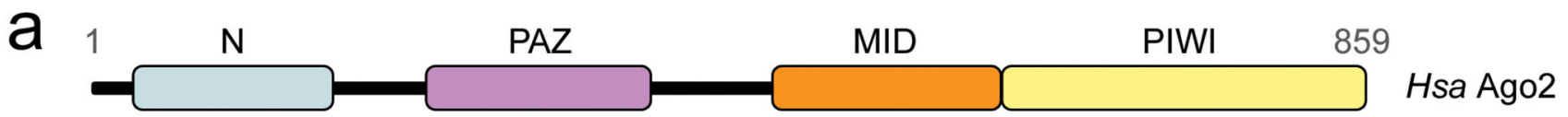

b
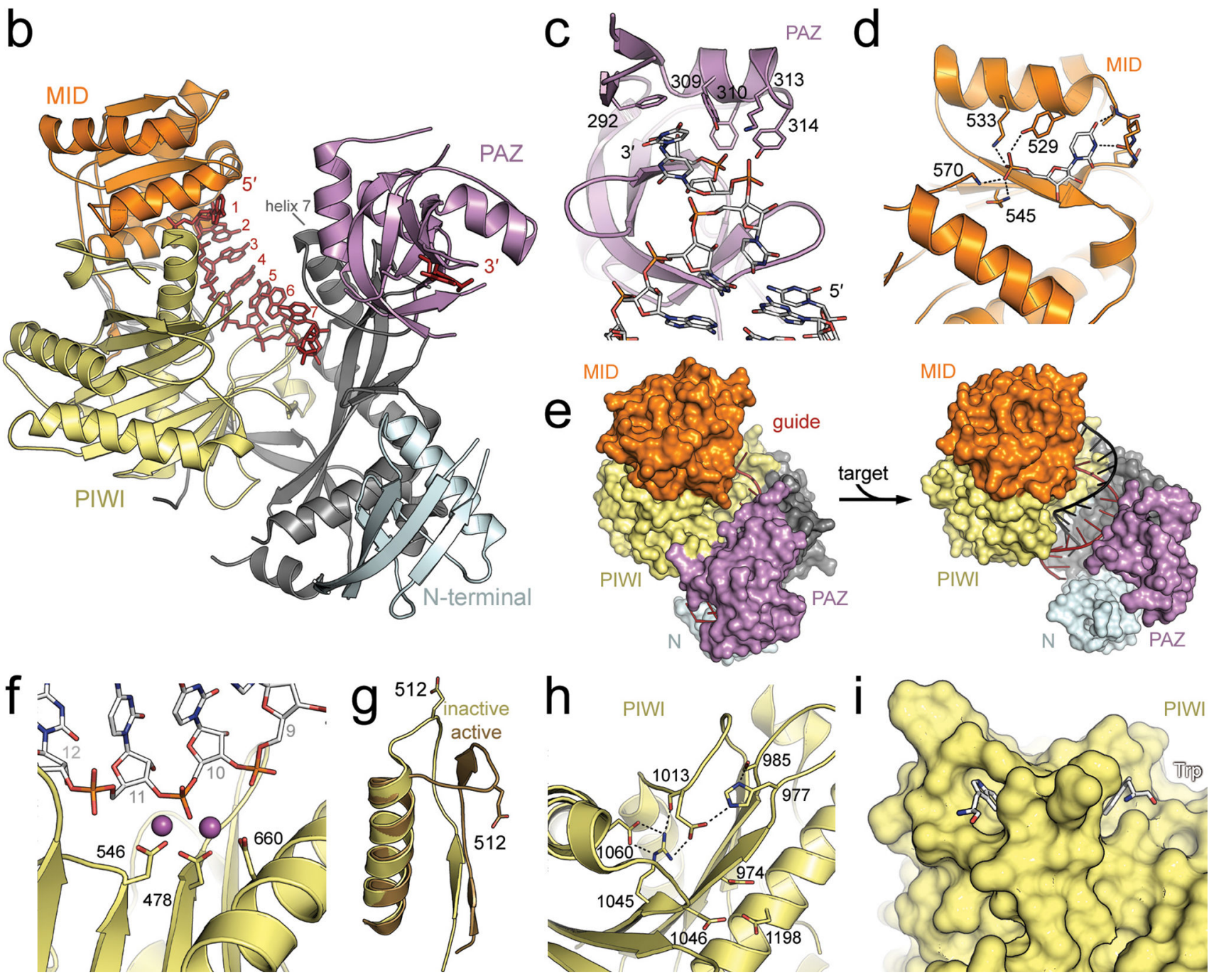

Figure 5.

Snapshots of RISC in action. (a) The domain structure of Argonaute is relatively well conserved in the AGO clade. PIWI clade proteins lack the N and PAZ domains. (b) The crystal structure of human Ago2 bound to an RNA guide strand (PDB ID: 4EI1). The seed region (nt 2-6) is pre-arranged in A-form geometry while the downstream portions of strand cannot be modeled due to disorder, as is typical in the absence of a target strand. Helix 7 is observed to rest against guide strand bases 6 and 7, distorting their geometry and providing an apparent barrier to target binding that is presumably circumvented via a conformational change. (c) The PAZ domain of human Ago2 recognizes the $3^{\prime}$-terminal $2 \mathrm{nt}$ overhang typical of helices involved in RNAi (PDB ID: 1SI3). Conserved residues contacting the $3^{\prime}$ terminus are represented as sticks and labeled. A hydrophobic pocket receives the terminal nucleobase. Nucleotides from the $5^{\prime}$-terminus can be seen in the bottom right, making only slight contact with the PAZ domain. (d) The MID domain is responsible for recognition of a 
phosphorylated 5'-terminus (PDB ID: 3LUJ). This UMP-bound crystal structure reveals the polar contacts that drive phosphate recognition as well as elucidating the base-specific contacts that grant the MID domain its preference for a $5^{\prime}$-terminal A or U. (e) A pair of $T$. thermophilus crystal structures illustrate a conformational change that results upon extensive base pairing between guide and target (PDB ID: left, 3DLH; right, 3HM9). RISC binding to a $19 \mathrm{nt}$ target strand allows formation of an A-form helix that induces release of the guide strand's 3 '-terminus from the PAZ domain along with a drastic opening of the two Argonaute lobes. The target-bound model shows that the $\mathrm{N}$ domain blocks formation of a longer helix. ( $f$ ) In the catalytic center of $T$. thermophilus Argonaute's PIWI domain, three aspartic acid residues coordinate a pair of $\mathrm{Mg}^{2+}$ ions for cleavage of the target strand, shown as white sticks with nucleotides numbered in gray (PDB ID: 3HVR). ( $g$ ) In T. thermophilus the target-induced conformation change also involves reorientation of L2, which contains a glutamic acid residue. If target binding is incomplete or absent, the inactive state is sampled (yellow). In the target-bound state (brown), the glutamic acid is deposited adjacent to the aforementioned catalytic triad, completing a tetrad typical of RNase H enzymes (PDB ID: bound to a $12 \mathrm{nt}$ target and inactive, 3HO1; bound to a $19 \mathrm{nt}$ target and active, 3HM9). (h) The pre-ordered catalytic tetrad as observed in the absence of target strand in $K$. polysporus Argonaute (PDB ID: 4F1N). Residue 1013 here corresponds to T. thermophilus residue 512. (i) The PIWI domain of human Ago2 bears two tryptophan binding sites that complement the side chain geometry expected from a GW protein binding partner (PDB ID: 4EI1). Free tryptophan was present in the crystallization conditions and the pair of bound amino acids is represented as sticks. 
a

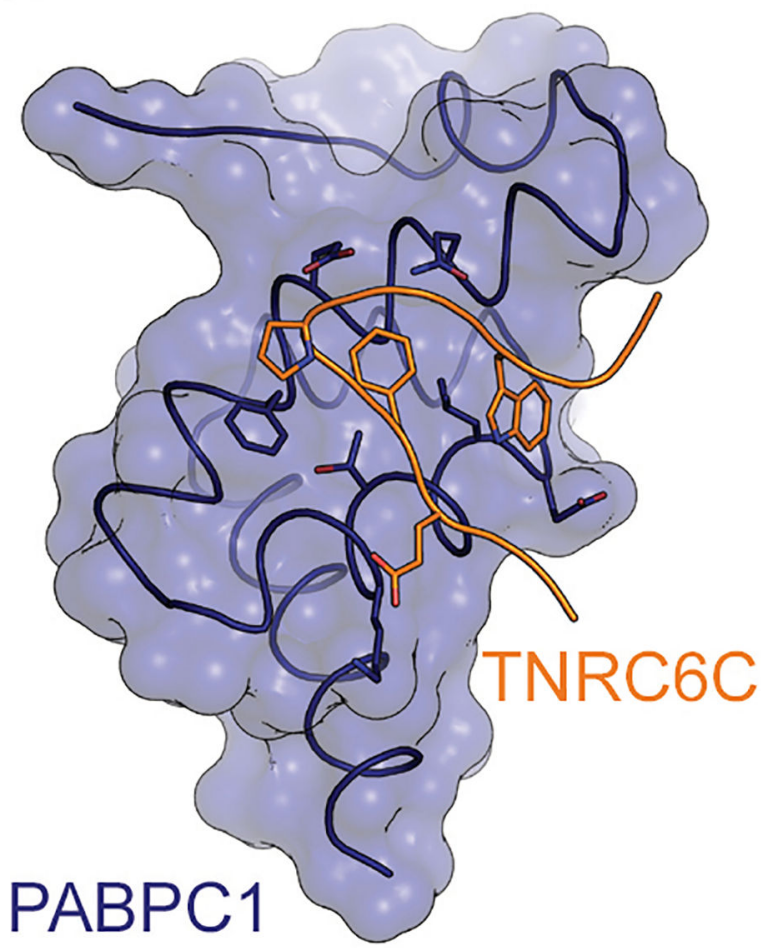

b

Translin

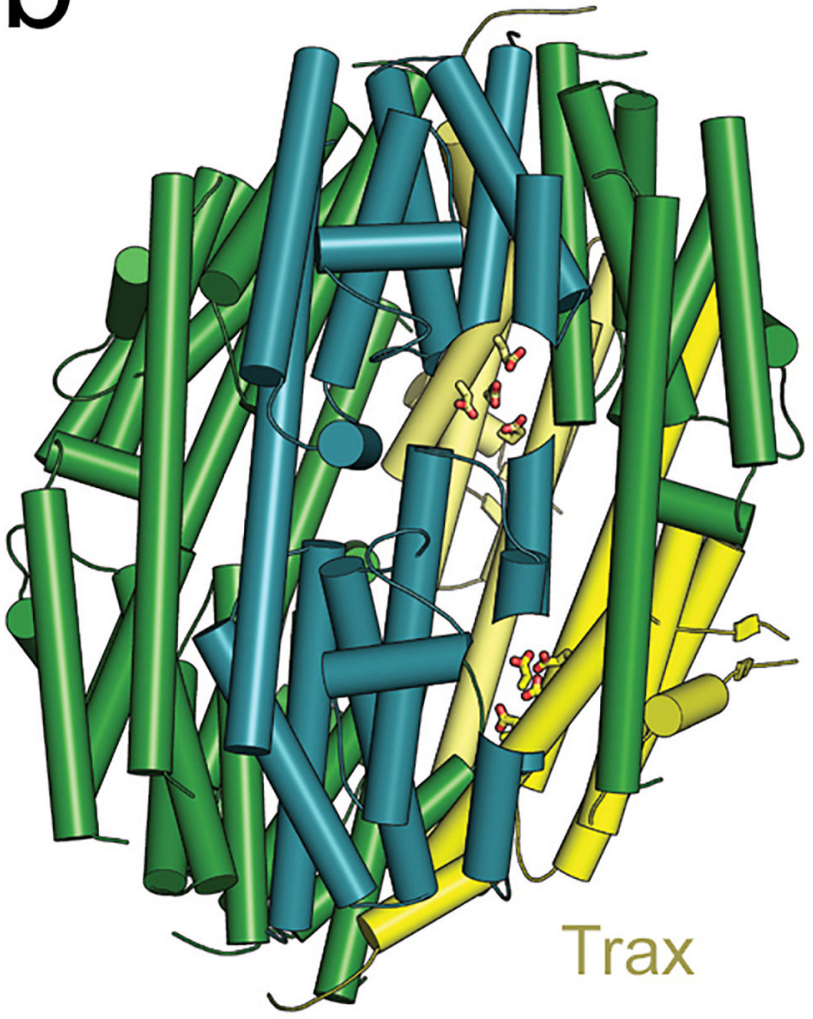

Figure 6.

Molecular assemblies in RNAi. (a) The interface between the C-terminal portion of PABPC1 and the DUF of TNRC6C, a GW protein (PDB ID: 2X04). Interacting side chains are shown as sticks. (b) The human endonuclease C3PO comprises hetero- and homodimers of Trax (yellow) and/or Translin (green or teal). The teal-colored Translin homodimer in the foreground is partially cut away to reveal the side chains of Trax's active site, rendered as sticks. In this crystal structure, the complex adopts a hollow, egg-like shape with no obvious means for its passenger strand substrate to access the enclosed active sites (PDB ID: 3PJA). 